This article was published in The International Journal of Life Cycle Assessment, 19 (7),1382-1408, 2014

http://dx.doi.org/10.1007/s11367-014-0746-x

\title{
Life cycle assessment of alternatives for recycling abroad alkaline batteries from Portugal
}

\author{
Susana Xará \& Manuel Fonseca Almeida \& Carlos Costa
}

S. Xará

Faculty of Biotechnology, Portuguese Catholic University, Rua Dr.

António Bernardino de Almeida, 4200-072 Porto, Portugal e-mail: sxara@porto.ucp.pt

M. F. Almeida: C. Costa

Laboratory of Process, Environmental and Energy Engineering,

Faculty of Engineering, University of Porto, Rua Dr. Roberto Frias, 4200-465 Porto, Portugal

\begin{abstract}
Purpose The European legislation establishes collection rates and states that all identifiable batteries must undergo treatment and recycling. Due to the inexistence in Portugal of recycling plants for alkaline batteries, those collected there have been sent to Austria and France, and currently, it is pondered to send them to Spain. This study aims to know the potential environmental impacts associated with the management of spent domestic alkaline batteries from collection in continental Portugal to recycling abroad.

Methods Three alternative recycling processes are considered: in Austria (A), France (F) and Spain (S). The system in study, from battery collection in continental Portugal to recycling abroad, includes complementary processes necessary for this circuit such as the production of boxes for battery collection and/or transportation and, for easiness of analysis and interpretation, is divided into: (i) container manufacture; (ii) distribution of empty containers; (iii) battery collection and sorting; (iv) international transport for the recycling; and (v) battery recycling. Recovered materials were also quantified. The LCA methodology and the method of impact assessment Eco-indicator 99, Hierarchist version, with two options, with and without inclusion of long-term emissions, were used. This method considers three damage categories: human health, ecosystem quality and resources, which group 11 impact categories.

Results and discussion For ecosystem quality, there is a preponderance of the impact of recycling processes $\mathrm{F}$ and $\mathrm{S}$ regarding all other processes and, in particular, regarding recycling process $\mathrm{A}$. After these, the container production impact is the most significant followed by the transport to Austria. For human health, there is a preponderance of the impact of recycling process $S$ followed by the impact of $\mathrm{F}$, and then of the transport to Austria and, only after, the impact of recycling process A. For resources, process S impact is higher than the one of A and this is higher than system F. The transport shows an expectable impact (highest for Austria, lowest for Spain), but for Austria and for France, it is higher than the impact of the recycling process itself.

Conclusions System $\mathrm{F}$ is the most negative in terms of eco- system quality and $\mathrm{S}$ is the worst in terms of human health. In these two damage categories, system A is the best but the worst in the
\end{abstract}


damage category of resources, where $\mathrm{F}$ is the best system. If the recovered materials are considered in this balance, the environmental advantage of system $\mathrm{A}$ is clear.

\section{Introduction}

The latest legislation on batteries, accumulators and their waste, Directive 2006/66/EC of the European Parliament and of the Council of 6 September 2006 (Official Journal of the European Union 2006), transposed into national law by the Portuguese Decree-Law No. 6/2009 of 6 January (Diário da República 2009), establishes as a global goal that the Member States (MS) shall, taking into account the environ- mental impact of transport, take the necessary measures to maximize selective collection of waste batteries and accumulators and to minimize the disposal of batteries and accumulators as mixed municipal waste, with the aim of achieving a high level of recycling for all wasted batteries and accumulators.

To achieve this objective, it establishes that MS should ensure the existence of appropriate collection systems for wasted batteries and accumulators and it defines a minimum collection rate of $25 \%$ by September 26, 2012 (under Portuguese law December 31, 2011) and $45 \%$ by September 26, 2016 (in Portugal, December 31, 2015). Moreover, it also establishes that all identifiable collected batteries and accumulators must undergo treatment and recycling that may be undertaken outside the MS concerned or outside the EU, provided that the transfer complies with the legislation in force. The efficiency levels to be achieved by recycling processes up to September 26, 2011 are defined too (for batteries and accumulators other than lead acid and nickelcadmium batteries, the minimum recycling efficiency level is $50 \%$ by mass).

The main objective of this Directive is to minimize the negative impact of batteries and accumulators and their waste on the environment, thus contributing to the protection, preservation and improvement of its quality (Official Journal of the European Union 2006). The interest for this subject has led to studies on the impact of management alternatives for spent batteries in many European countries such as in the UK (ERM 2006), Belgium (Briffaerts et al. 2006) and the Netherlands (AOO 2002a; 2002b). Also the European Commission has promoted studies in this area (European Commission 2009).

In Portugal, the collection of portable batteries started in the last quarter of 2003 (Ecopilhas, www.ecopilhas.pt), and by early 2010, Ecopilhas-Sociedade Gestora de Resíduos de Pilhas e Acumuladores, S.A., was the only management entity of an integrated system for portable batteries (Portuguese Environment Agency, www.apambiente.pt). It is a non-profit corporation, formed by the major producers and importers of batteries and accumulators that operate in the Portuguese market, and it has the function of ensuring the sustainability of the integrated system, managing a set of operations that perform separate collection, temporary storage, sorting and recycling (Ecopilhas, www.ecopilhas.pt). In 2007, batteries started to be sorted in Portugal. By 2008, Ecopilhas sent the alkaline batteries for recycling to Fernwärme Wien, Austria ( Ecopilhas, personal communication). Since the early 2009, the batteries were sent to the recycling plant Valdi in Feurs, France (Ecopilhas, personal communication), where in 2011, a serious accident took place which led to the temporary shutdown of this unit. Subsequently, sending the batteries to Spain began to be considered in Portugal as an alternative (Ecopilhas, personal communication). So far, there are no battery recycling plants implemented in Portugal.

This study aims to know the potential environmental impacts associated with spent domestic alkaline battery management from the collection stage in continental Portugal to recycling abroad, including in this analysis the complementary processes necessary as the production of boxes for 
the collection and/or transportation. Three alternative countries and recycling processes are considered: Austria, France and Spain. The year of 2007 was used as reference since it is the last one for which statistics and more detailed information on the management of these wastes are available.

Although the legislationjustrefers to recycling efficiencies to be achieved, taking into account that the Directive aims to minimize the negative impact of batteries and their waste in the environment and since there are many alternative processes, all out of Portugal, it makes sense to compare them in environmental terms for a more supported decision. The methodology used in this study is the life cycle assessment according to ISO 14040 (ISO 2006a) and ISO 14044 (ISO 2006b). Outside the scope of ISO, we have extended the impact assessment analysis to the damage categories established by Eco-indicator. The description that follows fulfils the requirements of these standards with the limitations, in length, inherent to a scientific paper. Obviously, the economic aspect plays an important role too, but it was not included in this analysis.

\section{Goal and scope definition}

\subsection{Goal definition}

The purpose of this study is to assess the potential environ- mental impact associated with the management of spent domestic alkaline batteries from collection in continental Portugal to recycling abroad. Three alternative processes for recycling are considered in Austria, France and Spain.

The results of the study and the information developed to carry it out (in particular, the screening of the processes covered and the identification and quantification of associated resources and emissions) have various applications. On one hand, it will enable to know the magnitude of the potential environmental impact of a system that includes the entire circuit from the collection of spent batteries in continental Portugal up to sending them for recycling abroad. This impact will be evaluated in terms of various environmental issues defined by impact categories taking into account the different processes included in the system. Thus, it will also be possible to compare the contribution of each process for the overall impact of the system, by category of impact and, therefore, to identify the processes with higher and lower impact. On the other hand, it will allow comparing the environmental performance of the three alternatives for recycling batteries, taking into account the mentioned environmental issues, which may therefore constitute a scientific support for deciding the best option for recycling this waste. Additionally, it will enable to identify the most significant environmental aspects and, consequently, the environmental advantages and disadvantages of each alternative, allowing for the identification and definition of opportunities for improving the environmental performance for each ofthem.

This study is intended to be useful to all those interested in knowing the potential environmental impact of recycling alternatives of the studied batteries and, particularly, to members of entities involved in the definition of environmental policies and the management of these wastes. It may be also useful for all those involved in these alternatives, such as professionals from the entities related to the different processes included in the study, i.e. from the manufacture of the boxes for battery collection to the recycling process itself, so they may know the environmental advantages and disadvantages (opportunities for improvement) of the processes. Since this study is part of a research project, it is expected that its results will be used in comparative statements for public disclosure, particularly in technical and scientific communications. 


\subsubsection{Systems under study}

The use of LCA in waste management is an application of this technique to a specific part of the life cycle of products. Thus, one may consider that the life cycle for the system under study begins with battery deposition/delivery by the consumer and ends when the emissions associated with the final destination of these batteries are an integral part of the environment and their resources are recovered.

Three alternative processes for recycling the batteries are considered; thus, three systems are defined:

System A: Recycling in Austria (Fernwärme Wien)

System F: Recycling in France (Valdi)

System E: Recycling in Spain (Recupyl)

As will be seen later, the only difference among these three systems is the recycling process itself, as well as the resulting products, and, obviously, the transport phase of the batteries to each recycling plant. The whole process of collection, including the production of the boxes used for deposition/delivery and/or transport of the batteries to the sorting plant, is the same for all three systems.

\subsubsection{Disposal/delivery of batteries by the consumers and the circuits for selective collection}

The system begins with battery deposition/delivery by the consumer in specific selective deposition places for subsequent collection by the competent authority (in the reference year of this study, the spent battery management, and so, the collection step were the responsibility of Ecopilhas). There are three types of disposal sites that are associated with the three channels of separate collection (Ecopilhas, personal communication):

- Kerbside bins and drop-off centres, with collection via municipal wastemanagement systems

- Hyper- andsupermarkets

- Eco-partners(other entities, retailersand institutions)

When deposition occurs in a Kerbside bin or drop-off centre, the local collection responsibility belongs to the respective municipality (being carried out by itself or by a contracted entity). It is only after packing the collected batteries in boxes provided and having them in temporary storage that Ecopilhas makes the collection.

The hyper- and supermarkets are required to have at their facilities, in a well-identified and accessible site, specific containers to accept from the final consumer the batteries and accumulators of the types they market. Boxes for selective deposition are provided to them free of charge and collection is ensured at appropriate intervals provided that the amount is not less than $100 \mathrm{~kg}$.

The eco-partners are public or private entities directly or indirectly involved in the consumption of batteries and accumulators that want to collaborate in the collection of spent batteries and accumulators. Included in this category are retailers (tobacconists, jewellery and watch shops, 
photography, household appliances, audio visual equipments, toys and informatics materials shops and others), public administration bodies, schools and universities, hospitals, health centres, clinics and rehabilitation centres among others. In the case of eco-partners, the operation is similar to the previous one, with boxes provided and their collection performed whenever the amount of batteries exceeds $100 \mathrm{~kg}$.

The amount of batteries collected varies by region of Portugal; therefore, it was assumed in this study to be similar to its average between 2004 and 2007. With this purpose, the country was divided into the following five regions: Lisbon Region (LR); Littoral (LT), Porto Region (PR); Northern Interior (NI); Algarve (Al); and Southern Interior (SI).

\subsubsection{The containers for spent battery collection (Ecopilhas, personal communication)}

The containers for spent battery collection, known as 'pilhões', are provided by Ecopilhas (Fig. 1) and are produced in Portucel Embalagem-Albarraque, a company of the Europac Group.

The container itself has an approximate capacity of $25 \mathrm{~kg}$ of batteries and consists of two corrugated outer and inner boxes. The boxes are made from double corrugated board produced in the same plant, using paper raw material from Portuguese, Spanish and French paper mills belonging to the same Europac group. The inner box is made from brown liners and recycled flutings and the outer one, that is printed, is made from white liners and recycled semi-chemical and flutings. The inks used for printing are water-based and come from an Iberian company. In some cases, particularly in hypermarkets and supermarkets, the boxes are placed on supports (displays) also made from corrugated board. These pieces were considered marketing elements and, therefore, are not taken into account in the present study.

For expedition, the boxes are placed on pallets, banded and filmed, respectively with polyester strips from a multinational company and stretch film, suitable for packaging systems, purchased from a national company. These boxes are transported directly to the postal service located at the Supplier Market of Lisbon Region (known as MARL), by national transportation companies contracted by Portucel Embalagem, in vehicles of variable capacity. From there, they are dispatched to the various entities of collection, according to the orders provided by Ecopilhas.

\subsubsection{The battery collection}

Before the collection by Ecopilhas, the full containers can be packed on pallets that are involved in plastic wrap. Each pallet has a capacity of 36 containers making a total of $900 \mathrm{~kg}$ to $1 \mathrm{t}$ of batteries per pallet.

The pallets are made available by the entities receiving the batteries and usually are already used Europallets, also from the transport of batteries for recycling. The collection of batteries, properly packed and eventually palletized, is not scheduled.

Each receptor entity contacts Ecopilhas when a collection wants to be made. For example, a particular municipal solid waste (MSW) management system can ask to collect two pallets with containers. The minimum collection amount is $100 \mathrm{~kg}$ (four boxes). When Ecopilhas has a certain number of requests, it contacts the transportation company that defines the circuit and the type of transport to be used, typically a truck (large or small, depending on the load to be collected). After collection, the batteries are sent for a temporary storage unit located in Lisbon where the full boxes are palletized and filmed before being transported to the sorting unit (Ecopilhas, personal communication). 
2.2.5 The battery sorting in Resitejo and their packing for transport to the recycling unit (Resitejo, personal communication)

From the temporary storage in Lisbon, the batteries are sent to a sorting unit, specific for this purpose, located in the premises of the MSW management entity Resitejo, located in Chamusca (Ecopilhas, www.ecopilhas.pt). In this unit, the manual sorting takes place and the batteries are temporarily stored before being sent for recycling. Batteries arrive by truck, packed in boxes, palletized and filmed. The load of each truck, approximately $20 \mathrm{t}$ of batteries, will be sorted in approximately one week and a half.

Upon arrival, a forklift truck transports the loaded pallets to the place of sorting (very short distance) and there the opera- tors open the boxes. A conveyor belt feeds the silos and from there to the sorting operation. The batteries pass through a giant sieve where button batteries are separated. The others are manually sorted by visual identification of the chemical sys- tem. After sorting, the batteries are separately packed in plastic big bags, but the alkaline and zinc/carbon batteries are packed together.

Each big bag takes about $1,000 \mathrm{~kg}$ of batteries and is placed on a pallet for road transport, by truck, to the recycling plant. Each truck carries 22 big bags each time. The empty containers and palletizing films are sent for the MSW sorting unit of Resitejo where they are incorporated in the lots of material to recycle. The pallets are reused.

2.2.6 The battery recycling in Austria (Fernwärme Wien, personal communication; European Commission 2009)

The Fernwärme Wien battery recycling plant (FWW-BR plant) is situated at Fernwärme Wien's hazardous waste incin- eration plant Simmeringer Haide, Vienna. The Simmeringer Haide plant incinerates 100,000 ton per year (tpy) of hazardous industrial waste and 180,000 tpy of sewage sludge.

The FWW-BR plant processes about 3,000 tpy of spent batteries on base of a 7,000-hour per year (hpy) continuous operation. Fed batteries are mainly zinc carbon batteries, alkaline batteries and mixtures. As mercury is removed in the process, there is no limitation in the mercury content of the fed batteries. However, button cells and accumulators are separated beforehand and not fed to the FWW-BR plant.

The delivered batteries are dumped into a feeding bin (see Fig. 2). Via dosing belt conveyors and a vertical conveyor, the batteries are continuously fed into a rotary kiln. Ignited by small amounts of fuel oil, the batteries are treated at temperatures of approximately $650{ }^{\circ} \mathrm{C}$ for about $1 \mathrm{~h}$. During this process, the spent batteries disintegrate; carbon, zinc and manganese are oxidised; and heavy metals leave the kiln with the dust fraction of the flue gas.

After exiting the rotary kiln and passing the post- combustion and separation chambers, the remaining dry bulk material is discharged using a cooling screw. The cold material is then fed to a shredder by a bucket elevator. The shredded solid material is separated into a fine and a coarse fraction using a sieving machine. The coarse fraction is further separated by a magnetic separator into a magnetic (scrap metal) and a non-magnetic fraction (zinc/manganese oxide).

The off-gas passes a hot cyclone to remove most of the entrained solids and is then cleaned in a three-stage flue gas treatment system. As, because of the low temperature, combustion might not have been complete, and the off-gas contains hazardous components such as mercury, the off-gas of the FWW-BR plant is fed into one of the hazardous waste rotary kilns for final post-combustion 
at $1,200{ }^{\circ} \mathrm{C}$. Afterwards, it passes the same multi-stage gas cleaning system including an electrostatic filter, scrubbers, activated coal filter and nitro- gen oxide removal (SCR) as the flue gas out of the main hazardous waste treatment plant for final cleaning. This plant interconnection ensures that all emission limit values given by legal regulations can be met.

The process water used in the scrubbers of the FWW-BR plant is continuously substituted by fresh water. The waste- water is collected by the wastewater collection system from where it is pumped into the wastewater treatment station of the hazardous waste incinerator and treated together with the mainstream by stepwise precipitation using ironchloride, lime and TMT 15.

The scrap is sent to one of the Austrian steel plants. To separate clean scrap, two powder fractions are produced both containing a similar percentage of zinc and manganese that are further processed in a Waelz kiln process where zinc is recovered for use in the metal industry and a vitreous slag is formed which can be used in underground construction.

2.2.7 The battery recycling in France (European Commission 2009; ERM 2006; Briffaerts et al. 2006)

VALDI is a France-based recycling company, specialised in refining ferrous alloys and recycling batteries. VALDI Feurs mainly recycles used $\mathrm{ZnC}, \mathrm{Zn}$ air and alkaline batteries (Hg

$<500 \mathrm{ppm}$ ), but also by-products from metal processing and mineral by-products. Total capacity is 12,000 tpy. Batteries larger than $5 \mathrm{~cm}$ are treated at VALDI Le Palais. Mixed streams of used batteries are accepted by VALDI Feurs. In total, more than $90 \%$ of the batteries, offered for treatment, are effectively recycled by VALDIFeurs. Other battery types are sorted out and are sent to specialised recyclers.

At VALDI Feurs, batteries are added to liquid steel in an electric arc furnace, technically similar to the steel production from steel scrap (Fig. 3). Additives are lime and reducing agents (carbon waste, FeSi waste and other waste streams) used according to their availability as wastes with a negative price. The lime is needed for the slag thermodynamic balance. The reducing agents are needed to reduce $\mathrm{Mn}$ and $\mathrm{Zn}$ oxides and to carburize the FeMn charge.

Through the melting process, a thermal separation of volatile metals (zinc, mercury, cadmium, lead) from the ferrous ones is carried out. The gases are treated with active carbon and the zinc is recovered into a powder of zinc oxide (filter dust from the waste gas cleaning) used in the zinc metallurgy and chemical appliances.

Steel, manganese, nickel and copper are melted, yielded and recovered as an iron alloy used in the stainless steel industry. The mineral part called the slag is tapped separately, vitrified and is used as ore manganese substitute. The sold slag is used to produce a silico-manganese mix (which can be used as a deoxidiser and an alloying element in steel).

2.2.8 The battery recycling in Spain (European Commission 2009; ERM 2006; Recupyl España, personal communication)

Recupyl is a development process company located outside Grenoble, France. Different types of patents for recycling of special wastes have been developed by Recupyl. They have patented their alkaline and saline (AlMn, $\mathrm{ZnC}, \mathrm{ZnO}$ ) battery recycling process, called the RECUPYL ${ }^{\mathrm{TM}}$ process. The process uses hydrometallurgy for processing batches of mixed batteries, and the Recupyl industrial recycling plant is authorised to handle all kinds of used batteries.

Initially, batteries are sorted by size and shredded (Fig. 4). The mechanical treatment step that 
follows sifts and magnetically separates steel, paper and plastics from the shredded batteries, leaving a 'black mass'.

The black mass is subsequently treated with acid, resulting in a $\mathrm{Zn} / \mathrm{Mn}$ solution and the separation of mercury and other (non-ferrous) metals. Two alternative steps can then be used to purify the $\mathrm{ZnMn}$ solution. Using the traditional electrolysis step, zinc is separated from manganese using acid and electricity. Another newly developed purification step enables the separation of zinc and manganese salts.

The flexibility of the Recupyl process allows for various end products, the relative production of which is determined by local demand. The three different end products are:

Zinc manganese solution via chemical treatment

Zinc and manganese oxide via electrolysis

- Zinc and manganese salts via the 'new' process step

The process considered in the present study runs in Spain (Azuqueca de Henares) and is patented by Recupyl.

\subsubsection{System functions}

The function of the systems under study is to manage spent batteries from their deposition/delivery by the consumer in continental Portugal to material recovery in a recycling unit outside Portugal.

\subsubsection{Functional unit and reference unit}

In 2007, Ecopilhas collected 477 t of batteries of which 85 to $90 \%$ were alkaline (Ecopilhas, personal communication). Of these, $97 \%$ were collected in continental Portugal, the geographic collection boundary considered in this study. It was thus considered as a reference in this study the collection and treatment of $400 \mathrm{t}$ of household spent alkaline batteries collected in continental Portugal which corresponds to about 42,553 batteries (assuming an average mass of $23.5 \mathrm{~g} /$ battery).

\subsubsection{System boundary}

Previously, the processes belonging to the systems under study have been described with information collected from the involved entities. The processes that are part of the life cycle of the waste under analysis - household alkaline batteries - from deposition/delivery by the consumer until the emissions resulting from the management of these batteries are an integral part of the environment and some resources are recovered such as those considered in each system and, therefore, in this study. Figure 5 shows the processes considered in this study and their relationships. These are considered within the system boundary: the paper production (P1) for the manufacture of the corrugated cardboard used in the manufacture of the boxes; the transport of paper to the corrugated board manufacturing unit (P2); the manufacture of corrugated board for the inner and outer boxes of the containers (P3); the manufacture of the boxes (P3) and their preparation for dispatch (P4); the container distribution by the battery collection points (P5 and P6); the deposition/delivery of the batteries (P7) and their packing for collection (P8); the production of the stretch film (P15) used in packaging; the battery collection (P9) 
and transportation to the temporary storage (P10) and from there to the sorting unit (P11); the sorting process (P12) and the packing and transportation for the alternative recycling units (P13); and the recycling processes themselves (P14).

The production of materials and energy needed by the previous processes are also considered, in such a way that in and out flows of the studied systems are considered elementary. Any exception to this approach is fully justified in the inventory section.

It was considered that the recovered materials in recycling processes are likely to replace virgin materials to be used in other processes, which areidentified in the inventory. Thus, in these recycling processes, the environmental benefits associated with this material recovery are accounted for. This ac- counting is only indicative since one of the most common approaches in LCA studies is not to allocate this environmental advantage to the process in which the material is recovered but to the process where this is used instead of the virgin material.

For easiness of analysis and interpretation, the system was divided into: (i) container manufacture (P1 to P4); (ii) distribution of empty containers (P5 and P6); (iii) battery collection and sorting (P7 to P12 and P15); (iv) international transport for the recycling (P13_A, F and S); and (v) battery recycling (P14_A, F and S). Recovered materials were also quantified.

\subsubsection{Data requirements and data quality requirements}

Taking into account that the aim of the study is focused on assessing the potential environmental impact of alternatives for recycling spent batteries collected in continental Portugal, the data used must reflect this reality. Thus, in the characterization of each process, real data obtained from the entities involved in the waste batteries management was used. Published data and the Ecoinvent database(Ecoinvent 2010) were used in the inventories. In the latter data, appropriate changes were introduced, particularly in terms of the country's electricity matrix where each process takes place. These are properly identified.

\subsubsection{Allocation procedures}

In the present study, allocation procedures were used, particularly in the definition of the inventories of the different processes. These are clearly identified in the reference that supports the inventory of each process or flow.

\subsubsection{Impactcategories andimpactassessmentmethodology}

Taking into account the objective defined for the study, the impact assessment method chosen was that of Eco-indicator 99 (Goedkoop and Spriensma 2000), version Hierarchist. This method models the damages caused by the inventory results and considers three damage categories: (i) human health; (ii) ecosystem quality; and (iii) resources, which group 11 impact categories:

Damage to human health - caused by emissions of carcinogens, respiratory effects caused by the emission of organic and inorganic substances, damages to human health caused by climate change, human health effects caused by ionising radiation and ozone layer depletion Damage to ecosystem quality - caused by ecotoxic emissions, by the combined effect of acidification and eutrophication and by land occupation and land conversion Damage to resources-caused by 
extraction of minerals and fossil fuels

This method was chosen because it includes the environmental issues (impact categories) that we consider important to take into account in the type of system we are studying. Additionally, it is a very well-known and well-accepted method by the scientific community. The results are presented for each impact category.

Two available options were considered: without and with inclusion of long-term emissions (i.e. emissions that occur after 100 years) thus allowing to verify their contribution in the overall impact. In the latter case, the long-term emissions are evaluated as current emissions, i.e. the characterization factors used are the same. The long-term emissions should not be confused with the long-term effects of current emissions (Hischier et al. 2010).

\subsubsection{Interpretation}

Tomeet the defined objectives (Section 2.1), the interpretation includes the following: the analysis of the potential environ- mental impact of each system (i.e. each recycling alternative) with emphasis on the comparison of the contribution of all processes included in that system; the comparison of the impact of the recycling processes themselves; and also, the impacts avoided by materials recovered in each sys- tem. This analysis is done for each damage category and also for the different impact categories (Section 2.2.14) in order to determine the effect of each recycling alter- native and of the different processes in each environmental issue. In this analysis, the weaknesses of each system will be identified and the opportunities for improvement that can be set are seen here. Whenever possible, these impacts will be backtracked to the inventory, trying to identify the substances that most contribute to the results that were identified as upgradable.

\subsubsection{Assumptions, value choices and optional elements}

Given the complexity of the studied systems and processes involved, to carry out the present study, a number of assumptions that are clearly presented in the inventory section were made. A sensitivity analysis was conducted in order to analyse the importance of long-term emissions. For that, the results obtained including or excluding these emissions were com- pared (see Section 2.2.14).

\subsubsection{Limitations}

The characterization of the systems under study, their analysis in terms of inventory, the impact assessment and the interpretation are associated with the assumptions mentioned above. Thus, in relation to the limitations of the study, it could only be added that its result relates to the systems described in this work taking into account the assumptions referred and the knowledge limitations reflected in the databases and in the impact assessment methods used.

\subsubsection{Type of critical review}

Since the present study involves the comparison of battery management alternatives and it is planned to publish their results, the critical review was conducted by the co-authors of this research paper. The scope of this review is the overall study. This revision meets the requirements 
established in the standards.

\section{Life cycle inventory}

For each system under study, data for description and characterization and of all the processes identified with- in its boundary were collected. This characterization includes the identification and quantification of the in-put and output flows and the following categories of data had been considered:

- Inputs of energy, raw materials and auxiliaries

- Products, co-products and waste

- Emissions to air, discharges to water and soil

Primary and secondary data were used. In addition to all the information necessary to the description of the battery circuits, the characterization data of the battery collection processes, the manufacture of the boxes and the battery recycling process in Austria were collected directly in the companies involved (primary data). For the remaining recycling processes, published data (secondary data) was used. For the inventories of transport processes and materials and energy production, the Ecoinvent database was used (Ecoinvent 2010).

The calculations necessary to validate the collected data, to relate the data with the unit processes and with the reference flows of the functional unit were carried out. In the succeeding text, the assumptions and data used to conduct the inventory life cycle of each system (Fig. 5) are presented.

For easiness of analysis and interpretation, as previously mentioned, the system was divided into five sub-systems: (i) container manufacture, (ii) distribution of empty containers,

(iii) battery collection and sorting, (iv) international transport for the recycling and (v) battery recycling. Recovered materials were also quantified.

\subsection{Container manufacture (P1 to $\mathrm{P} 4)$}

This sub-system includes the production of the differentpapers (P1) required for the manufacture of the corrugated board to be used in the manufacture of the boxes (kraftliner brown, recycled fluting, kraftliner white, semi-chemical recycled and testliner white) and their transport (P2) to the plant where the manufacture of cardboard and boxes will take place (P3). Once produced, the boxes are packed on pallets, banded with polyester tape and filmed for dispatch (P4). Table 1 indicates the inputs of the processes, the source of data for inventory and the assumptions.

\subsection{Distribution of empty containers (P5 and P6)}

The boxes, produced in Portucel Albarraque, are transported to the post office services of MARL (P5, Fig. 5). From there, the boxes are dispatched for the different recipients (P6, Fig. 5). The inputs of the processes, the source of data for inventory and the assumptions are shown in Table 1. 
The distribution of the amount of alkaline batteries deposited in each region (P7, Fig. 5) was estimated based on information provided by Ecopilhas ( www. ecopilhas.pt) and corresponds to the average between 2004 and 2007. The box and film consumption was considered according to the amount of collected batteries. The full boxes are transported from each collection point to the Ecopilhas temporary storage located in Lisbon (P9). From the temporary storage (P10), batteries are transported by a large capacity truck to the sorting unit (P11). The sorting process (P12) occurs in a specific sorting unit located on the premises of the Resitejo in Chamusca (Section 2.2.5). Due to the lack of information, no consumables in the sorting unit were considered. Results from this process are the boxes, the stretch film and the pallets. The pallets are reused and the boxes and the film are sent for recycling. These are not further analysed. The inputs of the processes, the source of data for inventory and the assumptions are shown in Table 1.

\subsection{International transport to recycling (P13)}

The batteries are transported from the sorting unit to the recycling plant by truck. Each truck carries 22 pallets, i.e. about $22 \mathrm{t}$ of batteries (Resitejo, personal communication). Transportation distances were calculated with the tool avail- able in Google Maps (https://maps.google.com/). The source of data for the inventory of transportation was the Ecoinvent database (Spielmann et al. 2007) and the Transport, lorry $>32$ t, EURO4/RER was used. In the load, only the mass of batteries was considered.

\subsection{Battery recycling (P14)}

Until 2008, Ecopilhas resorted to Fernwärme Wien, Austria, for the recycling of alkaline batteries (Ecopilhas, personal communication). Since the early 2009, batteries were sent to the recycling unit of Valdi in Feurs, France (Ecopilhas, personal communication), where a serious accident which led to the temporary shutdown of this unit took place in 2011. Subsequently, sending the batteries to Spain began a hypoth- esis to be considered (Ecopilhas, personal communication). Thus, within the scope of this study, the alternatives named A, F and S, respectively, corresponding to recycling in Austria, France and Spain were taken into account. The unit in Spain was that of Recupyl, in Azuqueca de Henares.

\subsubsection{Recycling in Austria (P14_A)}

Both the description of the process and its characterization (identification and quantification of inputs and outputs) were obtained by contact with the company responsible (Fernwärme Wien, personal communication). Table 2 indicates the inputs and outputs of the process, the source of data for inventory and the assumptions. For the description of the process, see Section 2.2.6.

\subsubsection{Recycling in France (P14_F)}

Not being able to obtain data directly from the entity, published data in Briffaerts et al. (2006) was used. In Table 3 , the inputs and outputs of the process, the source of data for inventory and the 
assumptions are shown. For the description of the process, see Section 2.2.7.

\subsubsection{Recycling in Spain (P14_E)}

Not being able to obtain data directly from the entity, but having from it the information that the implemented system is patented by Recupyl and that it occurs in two mechanical and hydrometallurgical steps (Recupyl España, personal communication), data corresponding to the Recupyl process published in ERM (2006) was used. In Table 4, the inputs and outputs of the process, the source of data for inventory and the assumptions are shown. For the description of the process, see Section 2.2.8.

\section{Life cycle impact assessment (LCIA)}

As mentioned before, the method used to evaluate the impacts was Eco-indicator 99, Hierarchist version. A sensitivity analysis was conducted in order to analyse the importance of long-term emissions. For that, the results obtained including or excluding these emissions were compared (see Section 2.2.14).

Figure 6 shows the results of the impact assessment for each damage category (ecosystem quality, human health and resources), for the different processes, with- out and with inclusion of long-term emissions (graphics indicated with 'damage category_LT'). For ecosystem quality, there is a preponderance of the impact of the recycling processes $\mathrm{F}$ and $\mathrm{S}$ regarding all other processes and in particular regarding recycling process A. After these, the impact of the processes P1 to P4 (container production) is the most significant followed by the international transport of the batteries to Austria. Note that recycling process A has a considerably lower impact than the one of the other recycling processes and even lower than the impact of the battery transport for that location. Altogether, the impact of transportation+ recycling process to system A lies below the other and even below recycling processes $\mathrm{F}$ and $\mathrm{S}$. When considering long-term emissions, an increase in the impact takes place.

For human health damage category, there is a preponderance of the impact of recycling processes S. In opposition to the previous damage category, here, the impact of S is much higher than $\mathrm{F}$, followed by the impact of the transport to Austria and only after that, by the impact of process A. There is a slight increase in impacts when considering the long-term emissions remaining in the relationship between the impacts of the different processes.

In terms of resources, the impact of the recycling processes is quite different and here the impact of process $\mathrm{S}$ is higher than that of $\mathrm{A}$ and is higher than the impact of process $\mathrm{F}$. The impact of transport shows an expectable contribution (highest for Austria and lowest for Spain), but for Austria and for France, it is higher than the impact of the recycling process itself and even higher than the impact of recycling process $F$. Together, considering transport+recycling process, system

A has the highest impact and $\mathrm{F}$ the lowest. There are no differences when long-term emissions are included. In summary, at the damage category level, system $\mathrm{F}$ is the worst in the ecosystem quality, system $S$ the worst in the damage category of human health and system $A$ the worst for re- sources. System A is the best in terms of impact on the ecosystem quality and human health and $\mathrm{F}$ is the best in the category of damage resources.

Figure 7 shows the results of the impact assessment for the impact categories that belong to the 
damage category ecosystem quality (acidification and eutrophication, ecotoxicity and land use), for the different processes, without and with inclusion of long-term emissions (graphics indicated with 'damage category_LT'). In this group, the highest impact is that of recycling process $\mathrm{F}$ in ecotoxicity, which explains the result for the impact of this process in this damage category.

In acidification and eutrophication, the highest impact occurs for recycling processes $\mathrm{S}$ followed by the impact of transport for $\mathrm{A}$. For recycling process $\mathrm{S}$, this is the dominant contribution to the result in this damage category. Together, the transport+recycling process, the impact of systems $\mathrm{A}$ and $\mathrm{F}$ come close and the one of $\mathrm{S}$ is higher. There are no differences when longterm emissions are included.

For ecotoxicity, the impact of process F stands out from all the others, followed by the one of $\mathrm{S}$ with less impact and about one third of the previous one. All the other processes have smaller impacts. In ecotoxicity, a slight increase in the impact already exists when long- term emissions are included.

In the transport to Austria, the impact observed for this damage category results from a close contribution of the impact from the two impact categories, acidification and eutrophication and ecotoxicity. In land use, the impact of the production of boxes stands out from all the others, including the recycling processes. This is the dominant contribution to the impact of these processes in this damage category: ecosystem quality. There are no differences when longterm emissions are included.

Figure 8 shows the results of the impact assessment for the impact categories that belong to the damage category of human health (carcinogenic, climate change, ionising radiation, ozone layer depletion and respiratory effects), for the different processes, without and with inclusion of longterm emissions (graphics indicated with 'damage category_LT').

The category of impact that has the highest contribution to the outcome in this damage category for all processes is the respiratory effects and the lowest is the ozone layer depletion. In the category respiratory effects, the impact of recycling process $\mathrm{S}$ stands out followed by the impact of transport to Austria (about four times lower). Again, system A is the only one for which the impact of transport is higher than the impact of the recycling process itself, but when combining transport and recycling process, it is higher than $\mathrm{F}$ but lower than $\mathrm{S}$. In the carcinogenics and ionising radiation impact categories, there is a predominance of the recycling processes regarding the others, and the impact of process $\mathrm{S}$ is the highest and $\mathrm{A}$ is the lowest in carcinogenics and $\mathrm{F}$ the highest and $\mathrm{A}$ the lowest in ionising radiation. In the climate change and ozone layer depletion impact categories, the recycling processes are more close to the impact of transports. For climate change, process $\mathrm{S}$ is dominant, followed by the one of $\mathrm{S}$, and the transport to Austria has a higher impact than that of the recycling process itself. When considering the recycling process and the transport, sys- tem $\mathrm{A}$ is the best and $\mathrm{F}$ the worst. The situation is quite different in the ozone layer depletion category in which the impact of recycling process $\mathrm{A}$ is dominant, followed by the one of its transport that is higher than the impact of recycling processes $\mathrm{F}$ and $\mathrm{S}$. Altogether, system $\mathrm{A}$ is the worst but the contribution of this impact category to the damage category in question is the lowest of all the categories, so that this influence is not noticed.

Figure 9 shows the results of the impact assessment for the impact categories that belong to the damage category of resources (fossil fuel and mineral extraction), for the different processes, without and with inclusion of long-term emissions (graphics indicated with 'damage category_LT'). In this case, the fossil fuels category determines the result for this damage category. In this one, the 
recycling processes have quite different impacts with system $S$ the highest followed by A and then $\mathrm{F}$, and the impact of transport to A exceeds the impact of the last two recycling processes. Altogether, in the transport+ recycling process, the impact of system A is dominant. In mineral extraction, process $\mathrm{S}$ stands out and $\mathrm{F}$ has the lowest impact. Transportation to Austria has an impact equivalent to that of its recycling process. There are no differences when long-term emissions are included.

\section{Life cycle interpretation}

Figure 10 shows, for each process, the contribution of each impact category for the outcome of the respective damage category, which facilitates the identification of improvement opportunities for each process and for each system, both by damage and by impact category.

For ecosystem quality damage category, the improvement of the environmental performance of systems $\mathrm{F}$ and $\mathrm{S}$, the most negative, would pass to decrease the impact of their own recycling processes. The improvement of system A may require decreasing the impact of the international transport for recycling or even of the manufacturing of boxes (P1 to P4). Going down to the level of impact categories, such an improvement in recycling processes $\mathrm{F}$ and $\mathrm{S}$ could be achieved by reducing the impact on ecotoxicity for the first and on the acidification and eutrophication for the second. The improvement in the impact of the set of processes $\mathrm{P} 1$ to $\mathrm{P} 4$ would be possible in terms of land use, while the impact of transport to Austria could be improved both in terms of acidification and eutrophication as in ecotoxicity Note that system A is the only one for which the impact of transport in all types of impact categories in this damage category is higher than that of the recycling process itself, which makes it difficult to identify improvements in the environmental performance of the system for this geographical location than improving the impact of the transport and, as already mentioned above, the impact of the manufacture of boxes (which would benefit the three systems). However, this system is the one with the lowest impact to this damage category.

For the damage category of human health, improvement of system $\mathrm{S}$ should focus also on its own recycling process and, for system A, mainly on the transport process. In terms of impact categories, improving process $\mathrm{S}$ and the transport to A would pass to decrease the impact on respiratory effects.

For the damage category of resources, all recycling processes and transport to $\mathrm{A}$ and $\mathrm{F}$, if improved, would bring advantages for their respective systems. In this case, the improvement would focus on the use of fossil fuels.

Figure 11 shows the results obtained to avoid impacts due to material recovery occurring in the recycling processes of batteries (and quantified by the potential impact of obtaining virgin materials). Process $\mathrm{A}$ is dominant in all damage categories and $\mathrm{S}$ is insignificant when compared to the previous one. Process F is be- tween the two. When considering the long-term emissions, the benefit to the damage category human health becomes much higher. Comparing Fig. 11 with Fig. 6, it can be seen that processes A and F have an extremely positive balance for any damage category. Process S presents a balance between the impact caused and prevented.

Considering all the assumptions made when carrying out the inventories of the different systems, it may be of interest to further analyse the impacts associated with products recovered and especially all processes that need to be involved in the production of ready-to-use secondary raw material. And despite the remarks made in Section 2.2.11, this is the current practice in LCA allocating these possible environmental advantages to the process in which the raw 
material is used and not to the one that recovers it.

\section{Conclusions}

The potential environmental impacts of the three alter- native systems for spent alkaline household battery management from their collection in mainland Portugal to recycling abroad in Austria (A), France (F) and Spain (S), using the LCA methodology and the method of impact assessment Eco-indicator 99, Hierarchist version with two options-with and without inclusion of long- term emissions, were quantified.

System $\mathrm{F}$ is the most negative in terms of ecosystem quality and $\mathrm{S}$ is the worst in terms of human health. In these two damage categories, system $\mathrm{A}$ is the best but the worst in the resources damage category, where $\mathrm{F}$ is the best system.

If the recovered materials are considered in this balance, the environmental advantage of system A is clear; however, it is a common practice in LCA to allocate this environmental ad- vantage to the system where the materials are used instead of virgin materials and not to the one where the materials are recovered. Thus, the choice of one of the processes will also depend on the priorities established in the environmental protection policy in force, particularly with regard to the protection of ecosystem quality, human health and resources. The influence of long-term emissions is significant only in the damage category of human health. Ecotoxicity is the impact category that most influences the results for the dam- age category of ecosystem quality, the respiratory effects for human health and the fossil fuels for resources.

The improvement of system $\mathrm{F}$ in the ecosystem quality damage category seems to be primarily at the level of the impact of the recycling process itself on ecotoxicity, and improving system $\mathrm{S}$ in human health would pass also by improving the recycling process itself at the level of the respiratory effects category. The improvement of system $\mathrm{A}$ in the resources category should be directed essentially at the level of consumption of fossil fuels in the transport, but also in the recycling process itself.

Acknowledgments The authors would like to thank the organizations and companies that contributed information and data necessary for the present work: Ecopilhas-Sociedade Gestora de Pilhas e Acumuladores, Lda; Portucel Embalagem, Albarraque-Empresa Produtora de Embalagens de Cartão, S.A.; Resitejo-Gestão e Tratamento dos Lixos do Médio Tejo; Fernwärme Wien Battery Recycling Plant; and Lipor- Serviço Intermunicipalizado de Gestão de Resíduos do Grande Porto.

\section{References}

Althaus H-J, Chudacoff M, Hischier R, Jungbluth N, Osses M, Primas A (2007) Life cycle inventories of chemicals. Ecoinvent Report N 8. Swiss Centre for Life Cycle Inventories, Dübendorf, Switzerland

AOO (Afval Overleg Orgaan) (2002a) Milieueffectrapport Landelijk Afvalbeheerplan 20012012. The Netherlands

AOO (Afval Overleg Orgaan) (2002b) Milieueffectrapport Landelijk Afvalbeheerplan Achtergronddocuemnt A5 Uitwerking afvalstroom "Batterijen (zinkbruinsteen \& alkaline)". The Netherlands 
Briffaerts K, Spirinckx C, Van der Linden A, Vrancken K (2006) Integrale Evaluatie Van Verwerkingstechnieken Voor Belgische Afvalbatterijen (Zinkkool - en Alkalinefractie). Study by VITO Commissioned by OVAM (Flemish Waste Authority), Mol, Belgium

Classen M, Althaus H-J, Blaser S, Tuchschmid M, Jungbluth N, Doka G, Faist Emmenegger M, Scharnhorst W (2009) Life cycle inventories of metals. Ecoinvent Report N 10. Swiss Centre for Life Cycle Inventories, Dübendorf, Switzerland

Diário da República (2009) Diário da República 1. ${ }^{\mathrm{a}}$ série - N. 3 - 6 de Janeiro de 2009. DecretoLei n. ${ }^{\circ}$ 6/2009 de 6 de Janeiro do Ministério do Ambiente, do Ordenamento do Território e do Desenvolvimento Regional

Doka G (2009) Life cycle inventories of waste treatment services. Ecoinvent Report N. 13. Swiss Centre for Life Cycle Inventories, Dübendorf, Switzerland

Ecoinvent (2010) Ecoinvent database v2.2. Swiss Centre for Life Cycle Inventories. Duebendorf. Switzerland

ERM (2006) Environmental Resources Management (ERM), Battery waste management life cycle assessment, study on behalf of DEFRA, Final report

Europac Group (Papeles y Cartones de Europa, SA) (2012) http://www. europacgroup.com/PT/Pages/default.aspx

European Commission (2009) Study on the calculation of recycling efficiencies and implementation of export article (Art. 15) of the Batteries Directive 2006/66/EC, Final report

Faist Emmenegger M, Heck T, Jungbluth N, Tuchschmid M (2007) Erdgas. In: Sachbilanzen von Energiesystemen: Grundlagen für den ökologischen Vergleich von Enegiesystemen und den Einbezug von Energiesystemen in Ökobilanzen für die Schweiz. Ecoinvent Report N. 6-V. Swiss Centre for Life Cycle Inventories, Dübendorf, Switzerland

FEFCO (European Federation of Corrugated Board Manufacturers) (2006) European Database for corrugated board life cycle studies. Brussels. Belgium

Frischknecht R, Tuchschmid M, Faist Emmenegger M, Bauer C, Dones R (2007) Strommix und Stromnetz. In: Sachbilanzen von Energiesystemen: Grundlagen für den ökologischen Vergleich von Enegiesystemen und den Einbezug von Energiesystemen in Ökobilanzen für die Schweiz. Ecoinvent Report N 6-XVI. Swiss Centre for Life Cycle Inventories, Dübendorf, Switzerland

Goedkoop M, Spriensma R (2000) Methodology annex: the Eco- indicator 99: a damage oriented method for life cycle impact assess- ment. PRé Consultants, Amersfoort, The Netherlands

Hischier R (2007) Life cycle inventories of packaging and graphical paper. Ecoinvent Report N 11. Swiss Centre for Life Cycle Inventories, Dübendorf, Switzerland

Hischier R, Weidema B, Althaus H-J, Bauer C, Doka G, Dones R, Frischknecht R, Hellweg S, Humbert S, Jungbluth N, Köllner T, Loerincik Y, Margni M, Nemecek T (2010) Implementation of life cycle impact assessment methods Ecoinvent report No. 3. Swiss Centre for Life Cycle Inventories, Dübendorf, Switzerland

ISO-International Organization for Standardization (2006a) ISO 14040: 2006, Environmental management—life cycle assessment— principles and framework. Geneva. Switzerland

ISO-International Organization for Standardization (2006b) ISO 14044: 2006, Environmental management-life cycle assessment—requirements and guidelines. Geneva. Switzerland

Jungbluth N (2007) Erdöl. In: Sachbilanzen von Energiesystemen: Grundlagen für den ökologischen Vergleich von Enegiesystemen und den Einbezug von Energiesystemen in Ökobilanzen für die Schweiz. Ecoinvent Report N 6-IV. Swiss Centre for Life Cycle Inventories, Dübendorf, Switzerland

Kellenberger D, Althaus H-J, Jungbluth N, Künniger T, Lehmann M, Thalmann P, (2007) Life 
cycle inventories of building products. Ecoinvent Report N 7. Swiss Centre for Life Cycle Inventories, Dübendorf, Switzerland

Nemeck T, Kägi T (2007) Life cycle inventories of Swiss and European agricultural production systems. Ecoinvent Report N 15. Swiss Centre for Life Cycle Inventories, Dübendorf, Switzerland

Official Journal of the European Union (2006) Official Journal L 266, 26/ 09/2006. Directive 2006/66/EC of the European Parliament and of the Council of 6 September 2006 on batteries and accumulators and waste batteries and accumulators and repealing Directive 91/157/ EEC

Portuguese Environment Agency (2007) Sistemas de Gestão de RSU - Dados gerais, Valorização e destino final

Spielmann M, Bauer C, Dones R, Tuchschmid M (2007) Transport services. Ecoinvent Report N 14. Swiss Centre for Life Cycle Inventories, Dübendorf, Switzerland
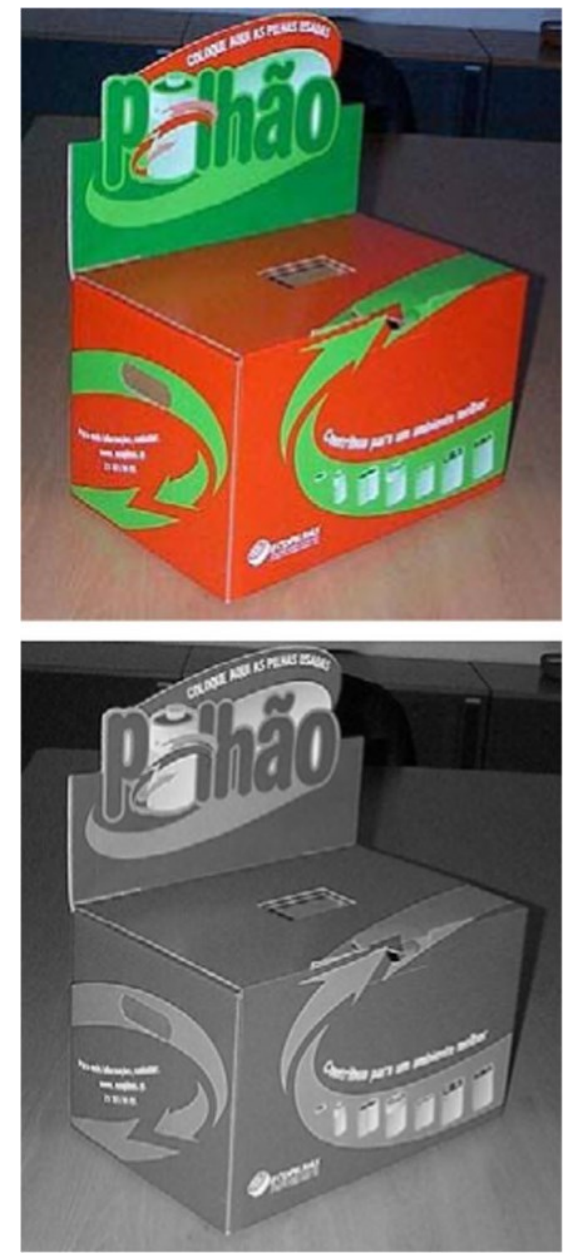

Fig. 1 Container for spent battery collection, consisting of inner and outer boxes (pilhão, in Portuguese) 


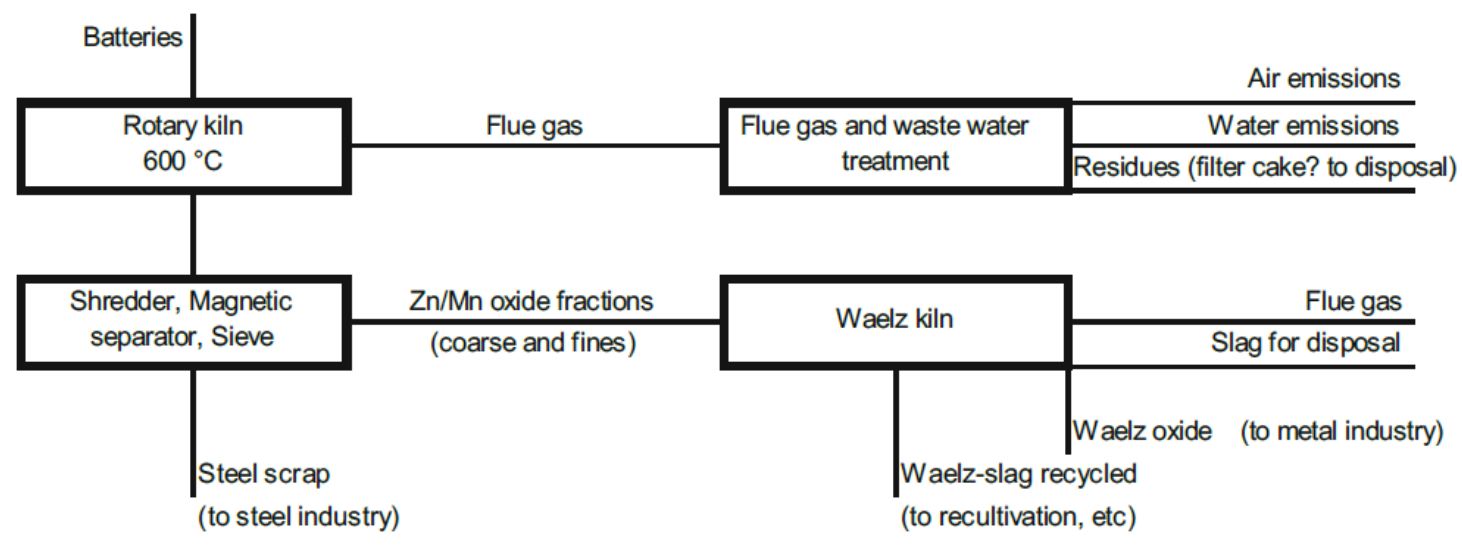

Fig. 2 Schematic representation of the battery recycling process in Austria

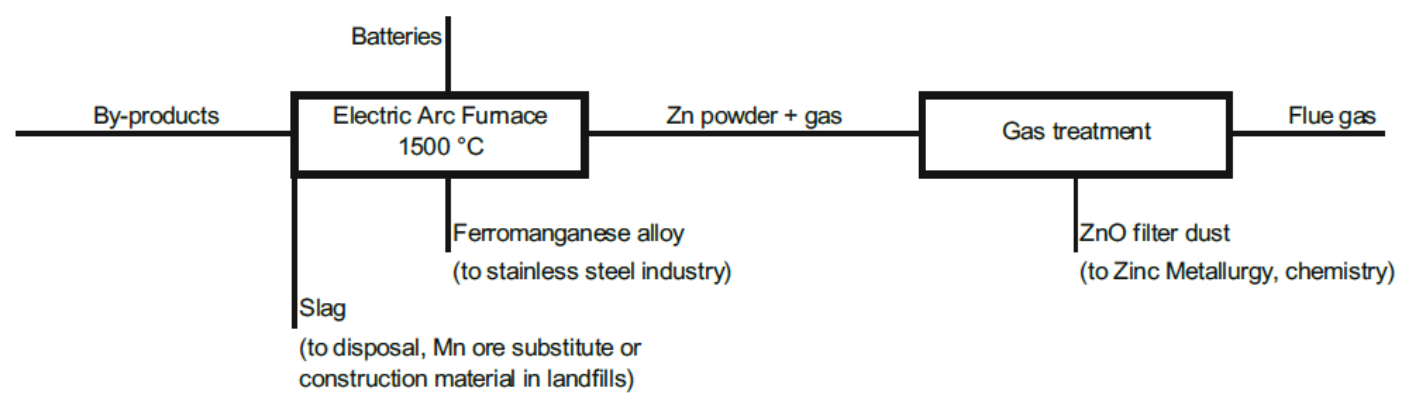

Fig. 3 Schematic representation of the battery recycling process in France

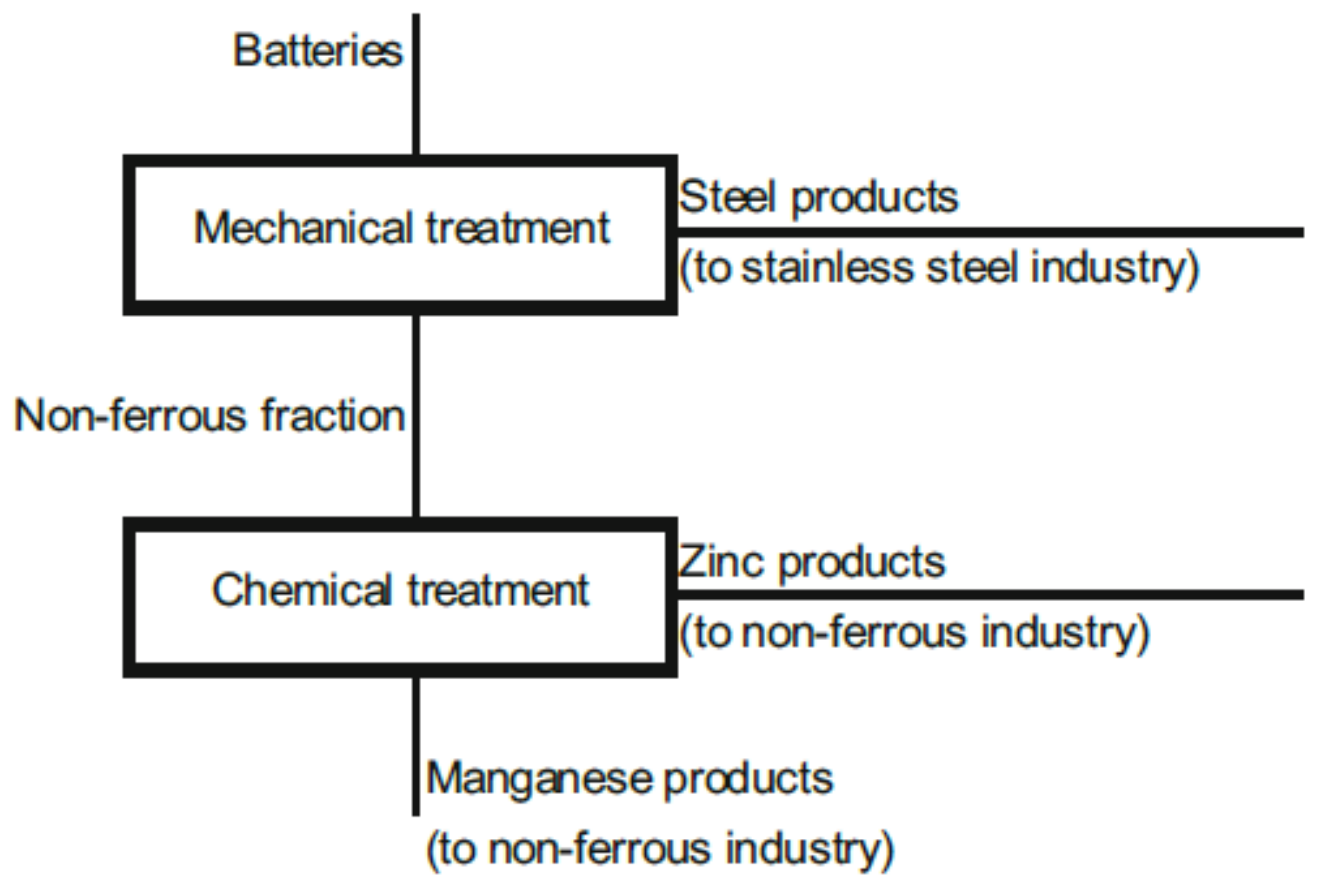

Fig. 4 Schematic representation of the battery recycling process in Spain 


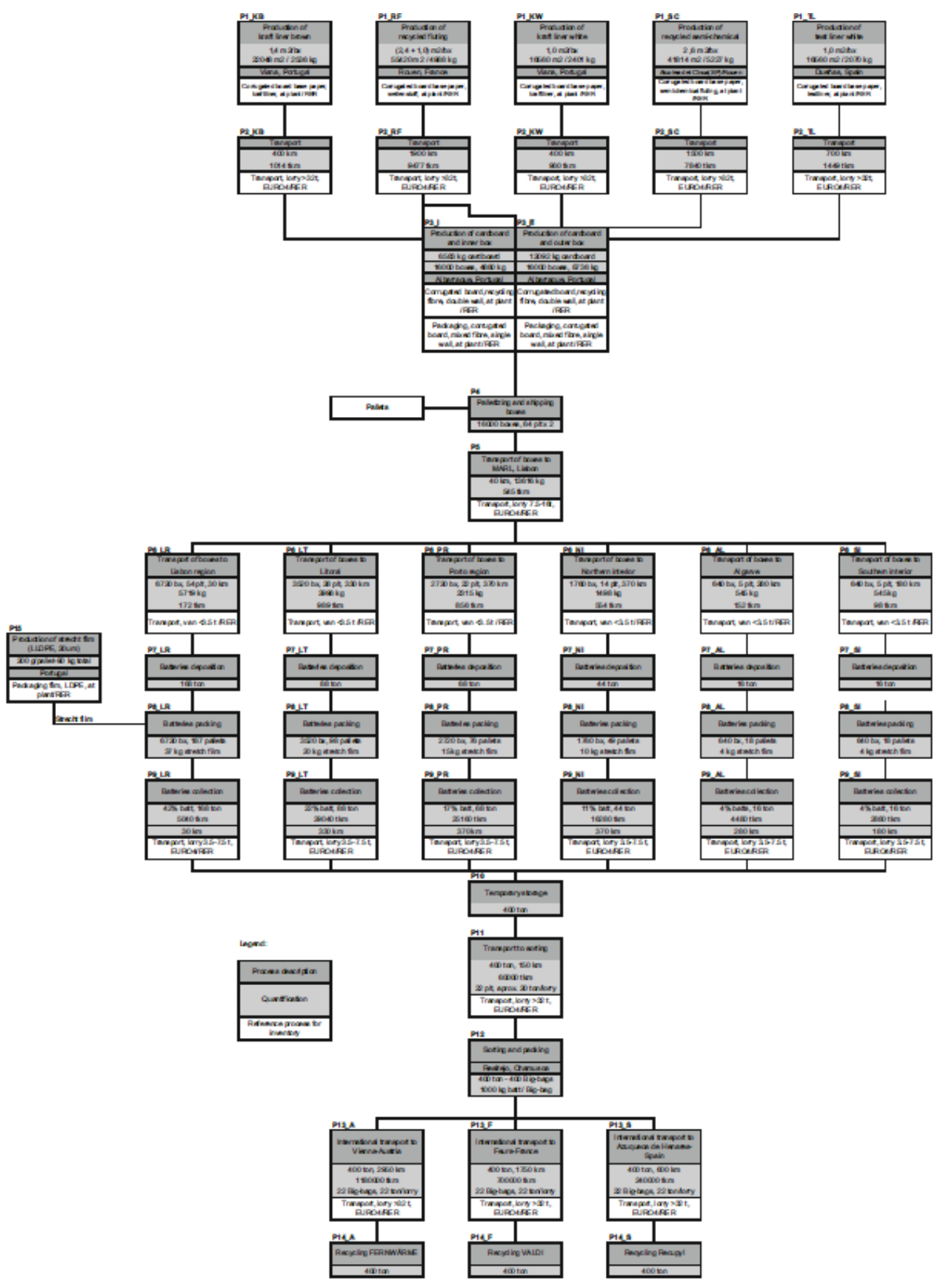

Fig. 5 Schematic representation of the processes considered in the study and their relationships 


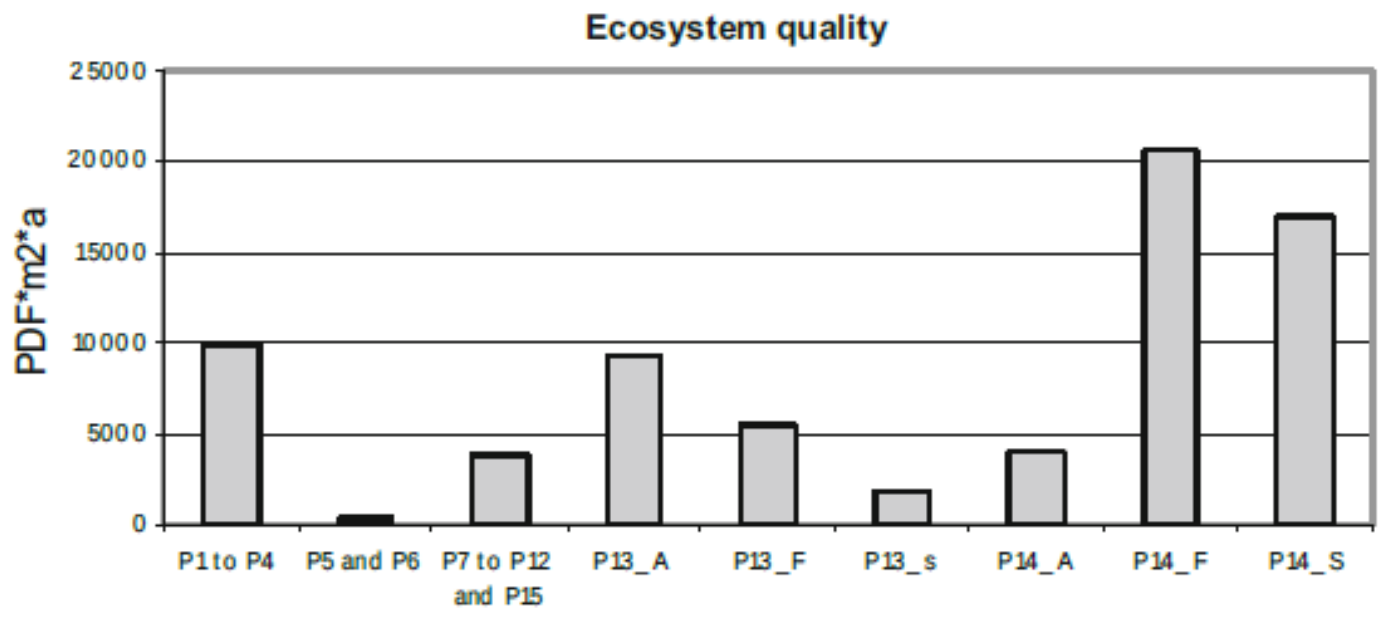

Processes

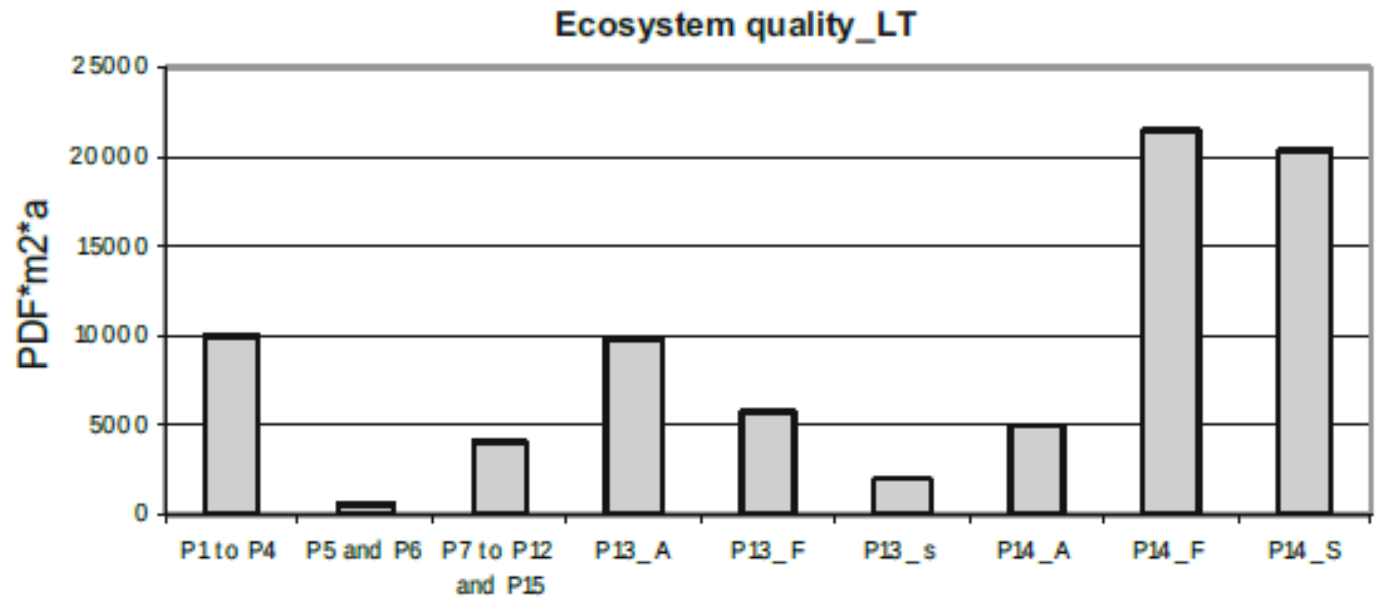

Processes

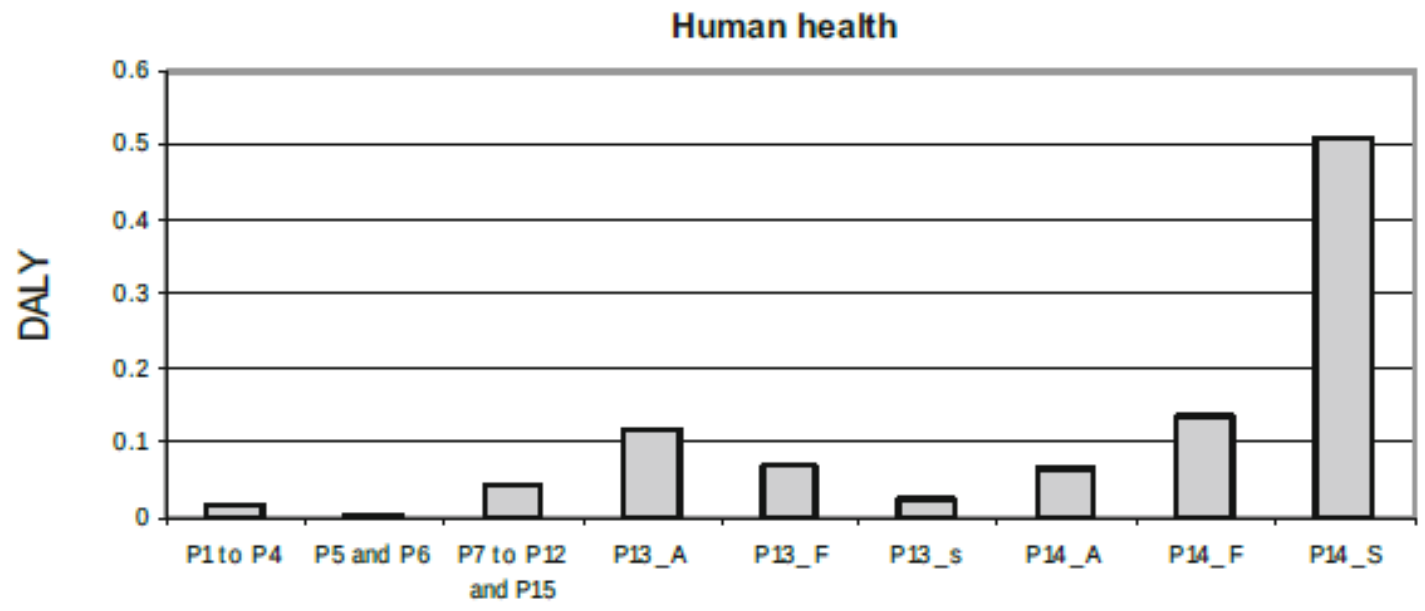

Processes 
Human health_LT

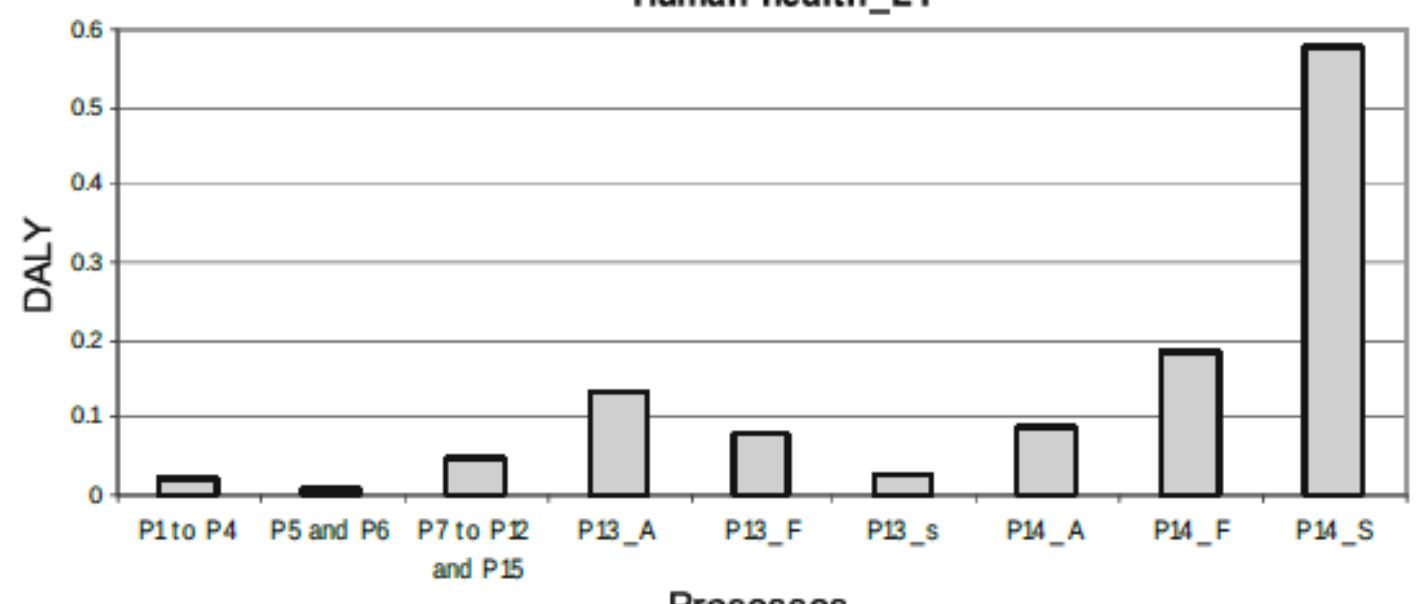

Processes
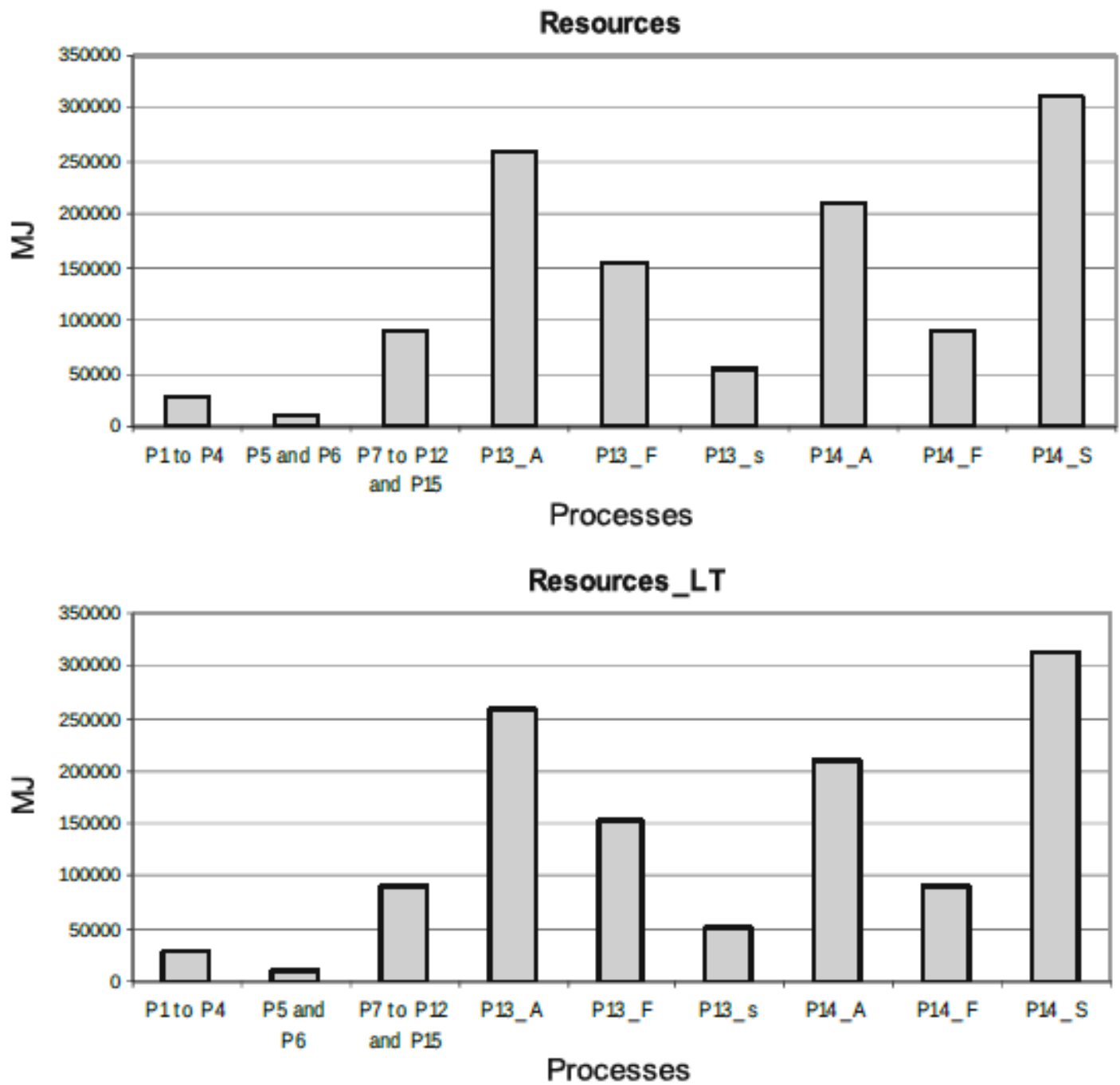

Fig. 6 Results of the impact assessment for each damage category (ecosystem quality, human health and resources), for the different processes, without and with inclusion of long-term emissions (graphics indicated with 'damage category_LT') 

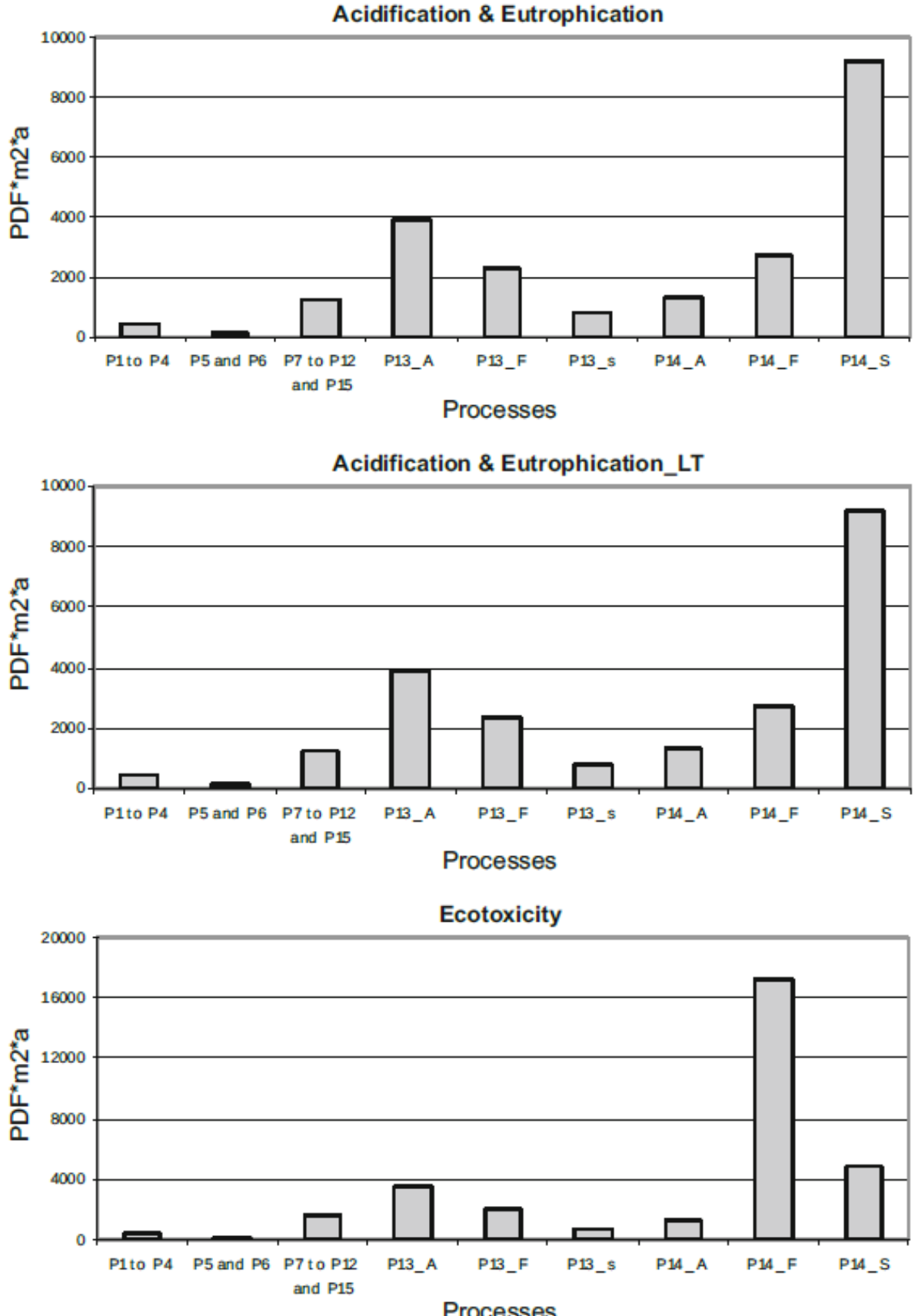


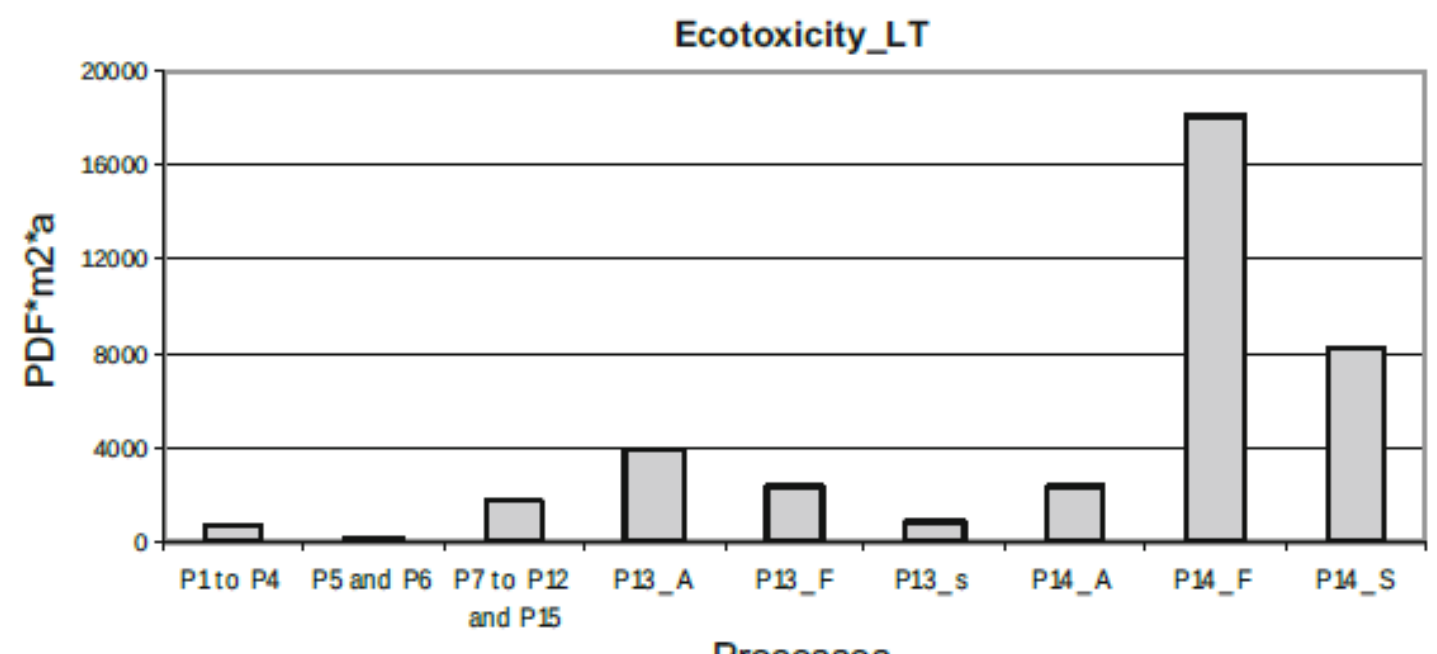

Processes

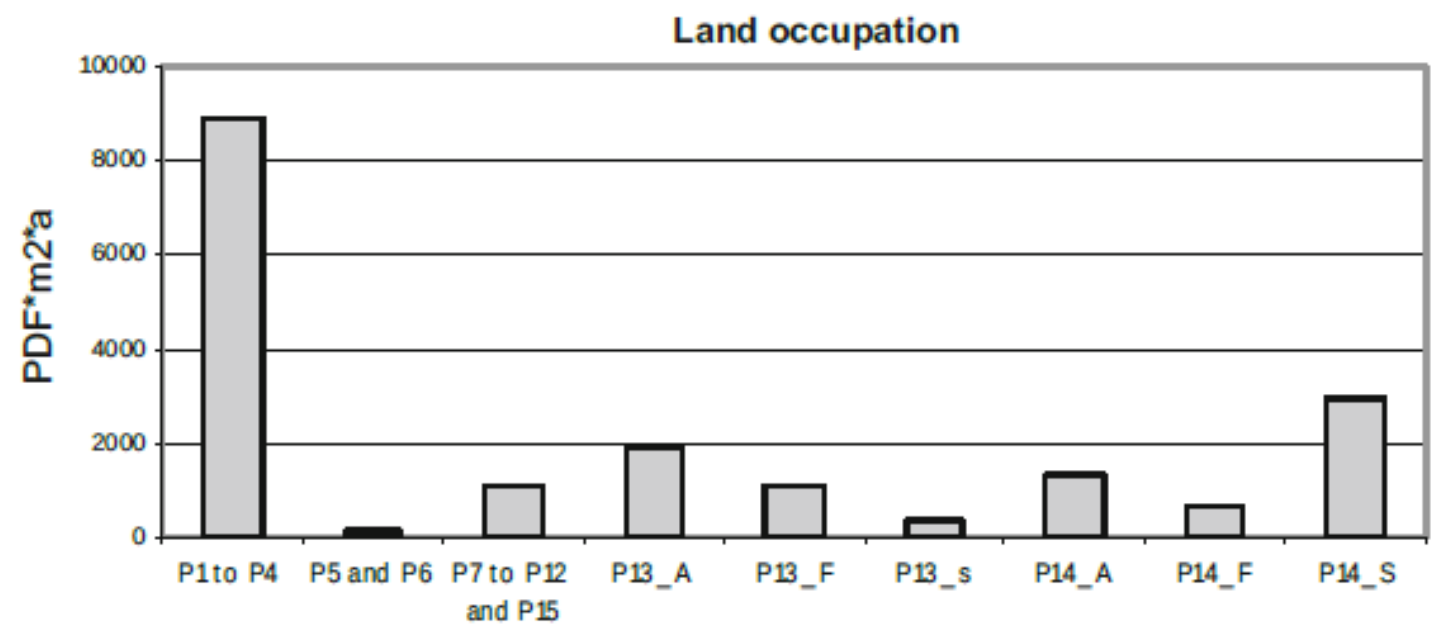

Processes

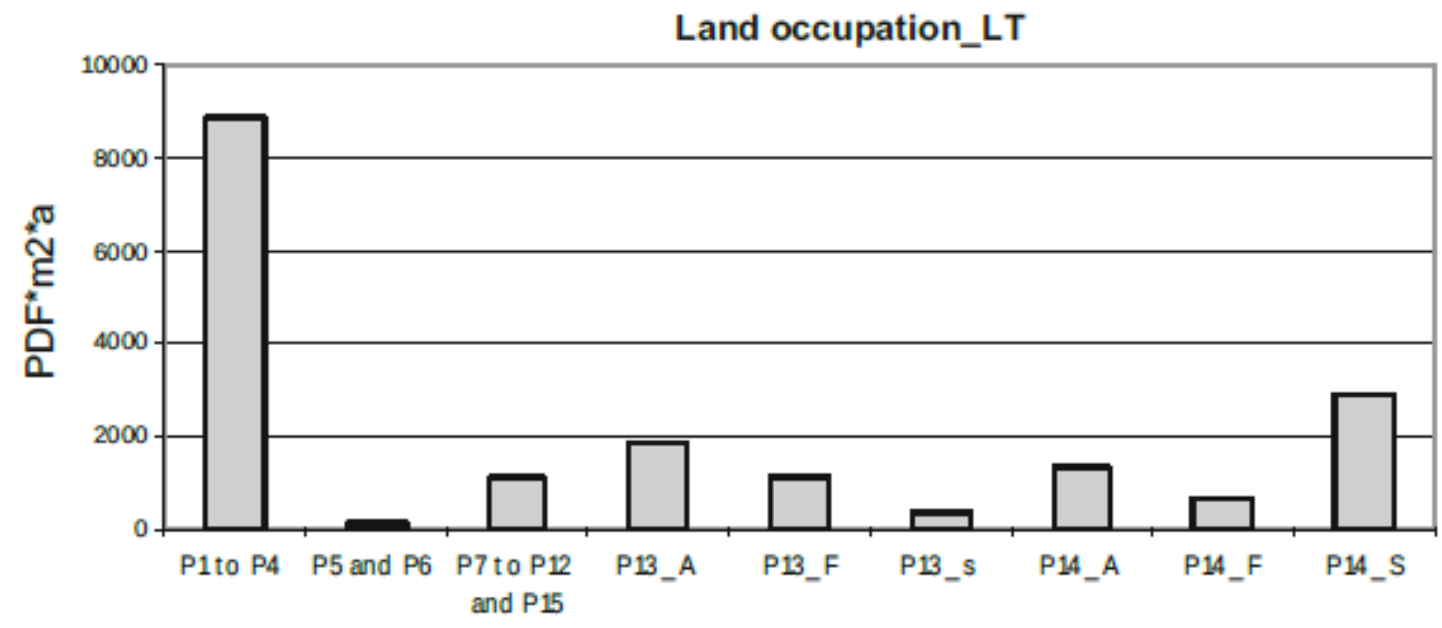

Processes

Fig. 7 Results of the impact assessment for the impact categories that belong to the damage category ecosystem quality (acidification and eutrophication, ecotoxicity and land use), for the different processes,without and with inclusion of long-term emissions (graphics indicated with 'impact category_LT') 


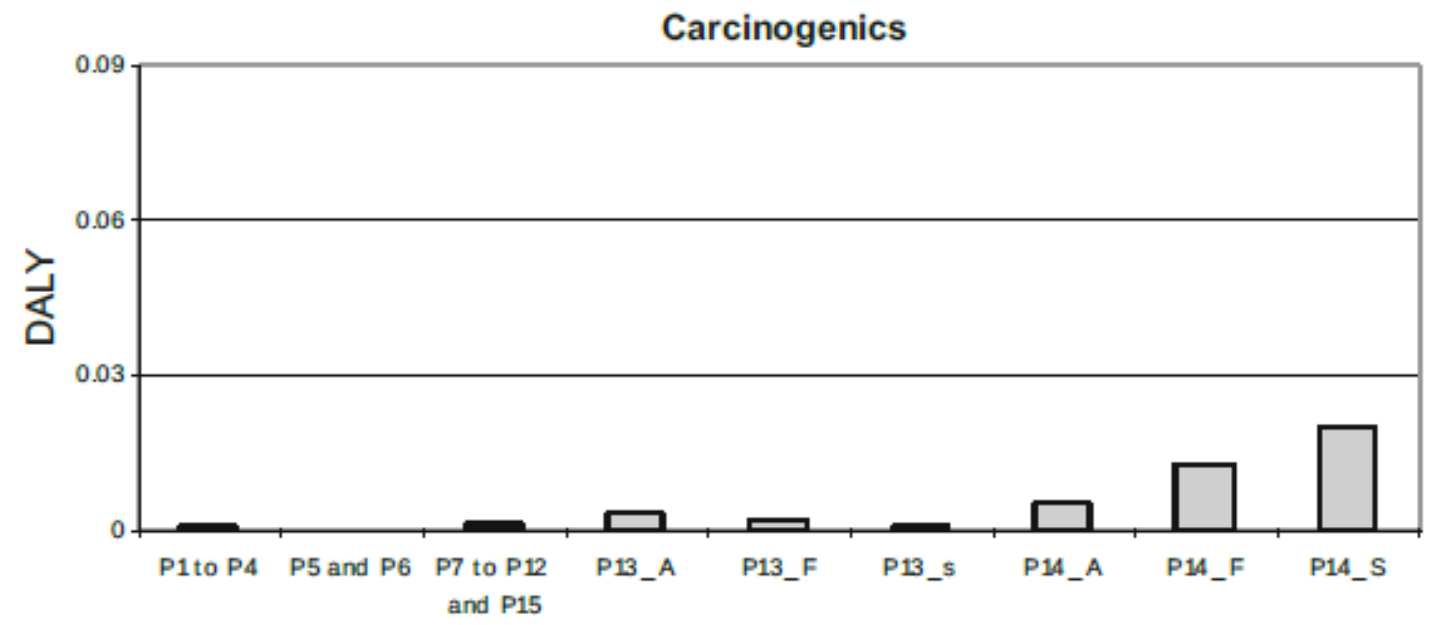

Processes

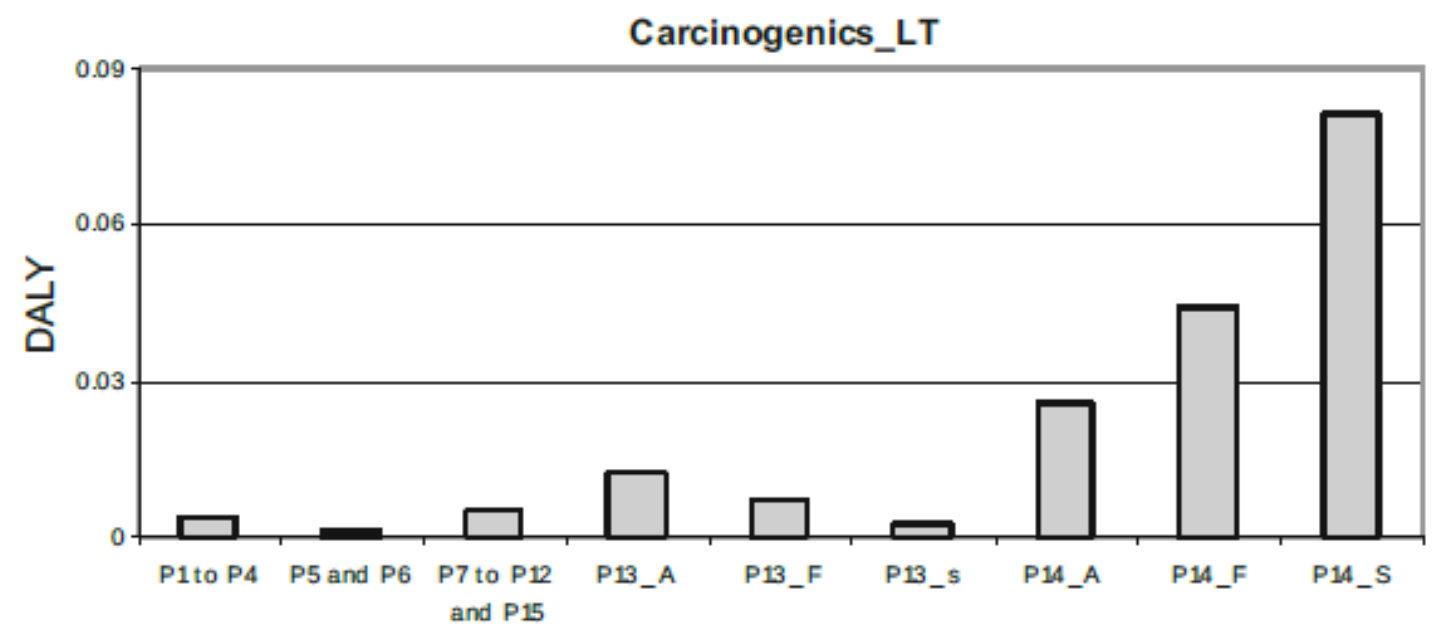

Processes

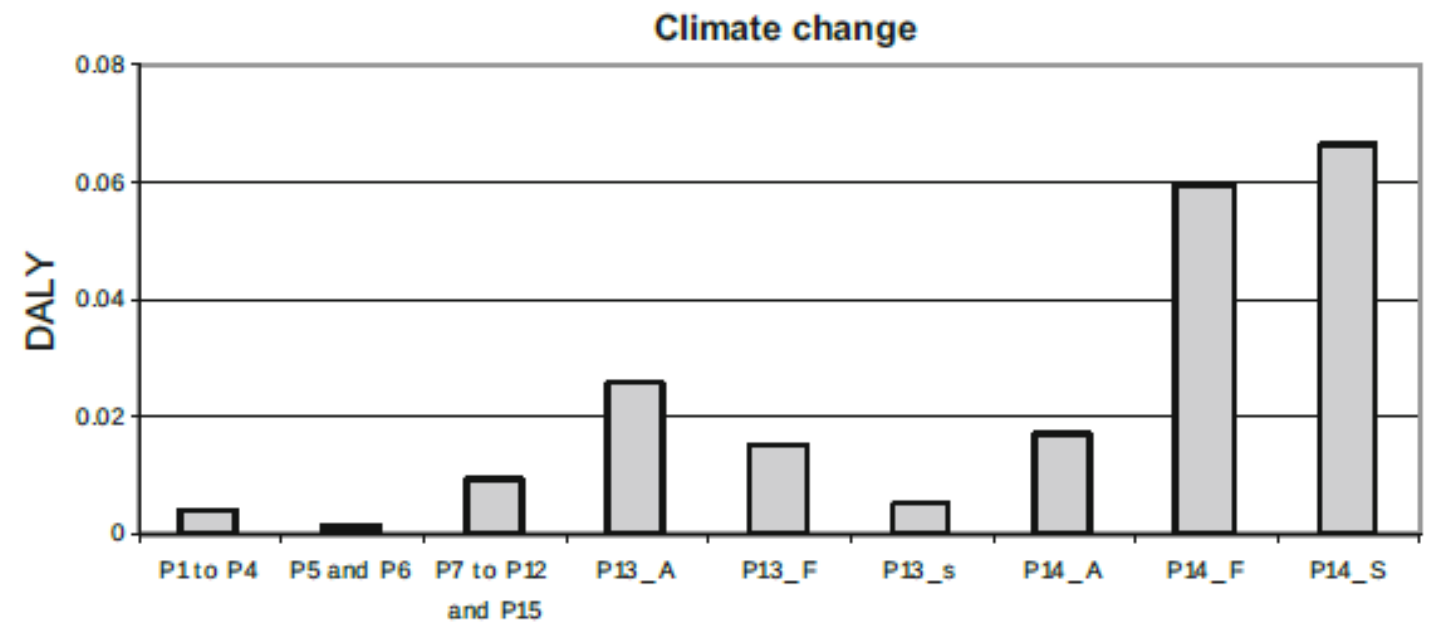

Processes 


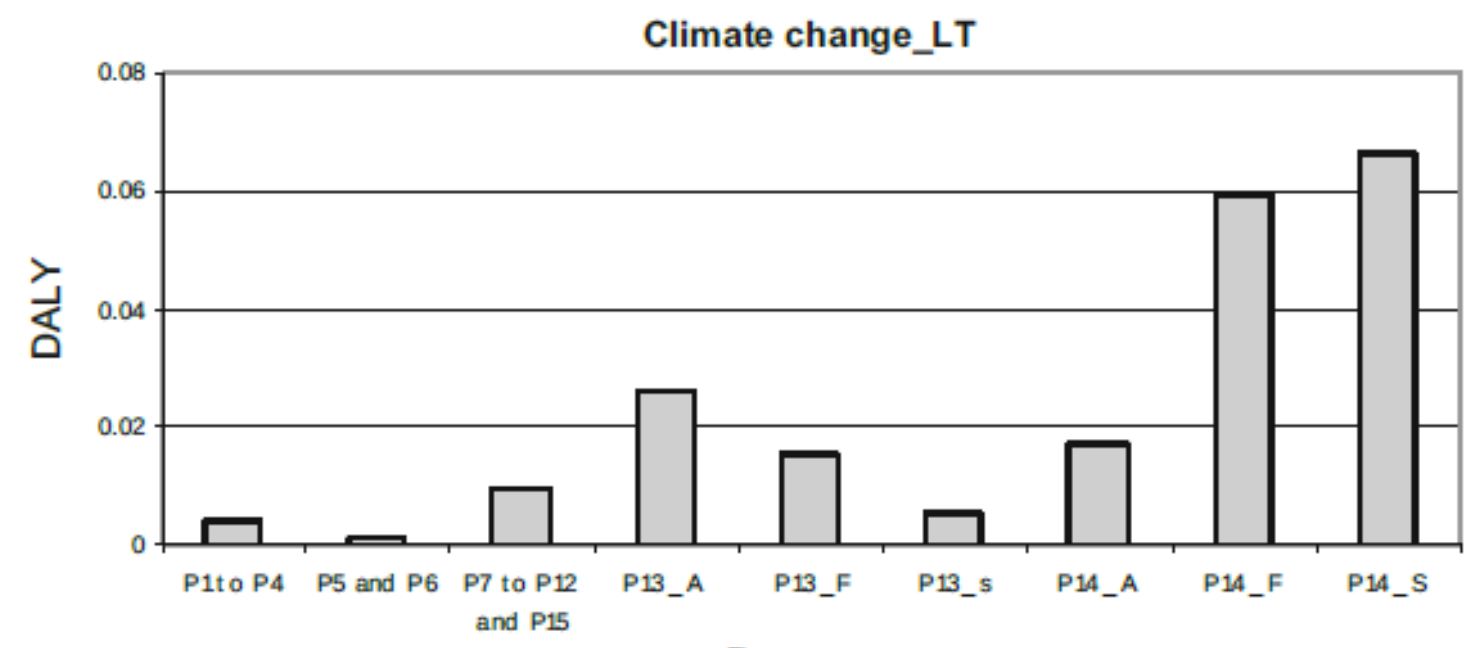

Processes

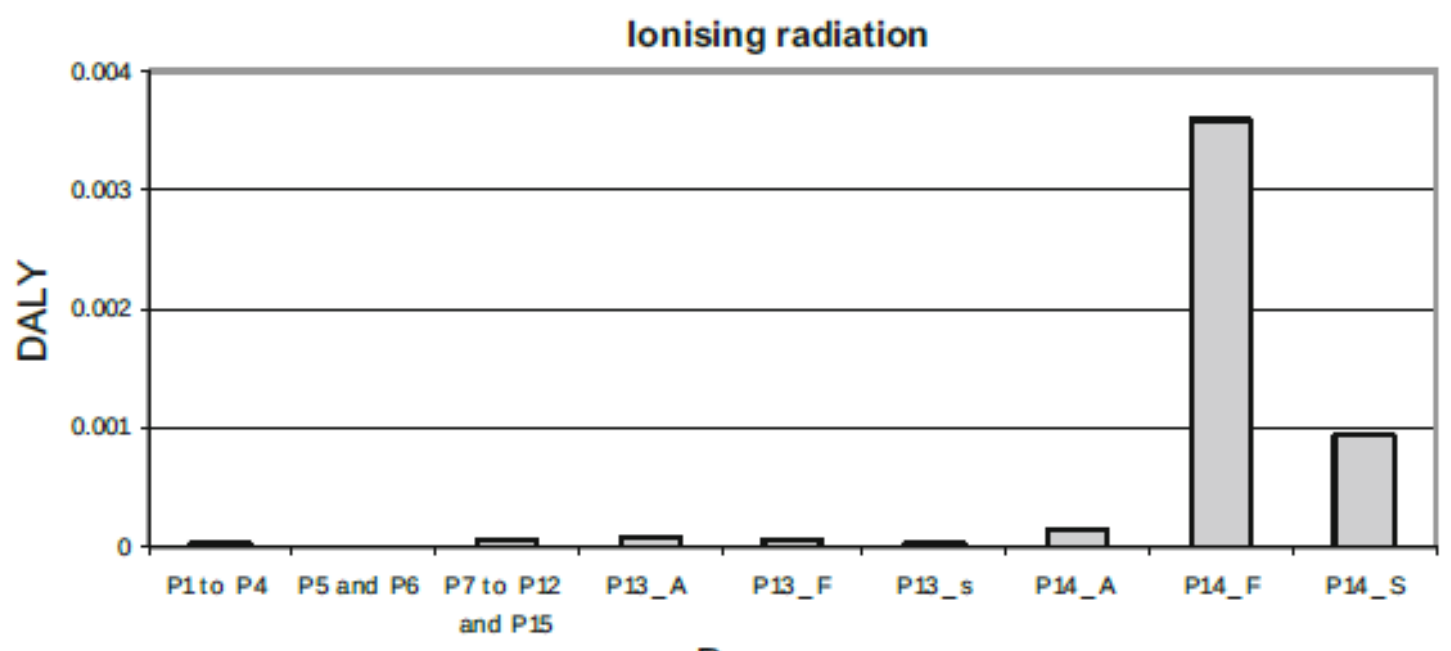

Processes

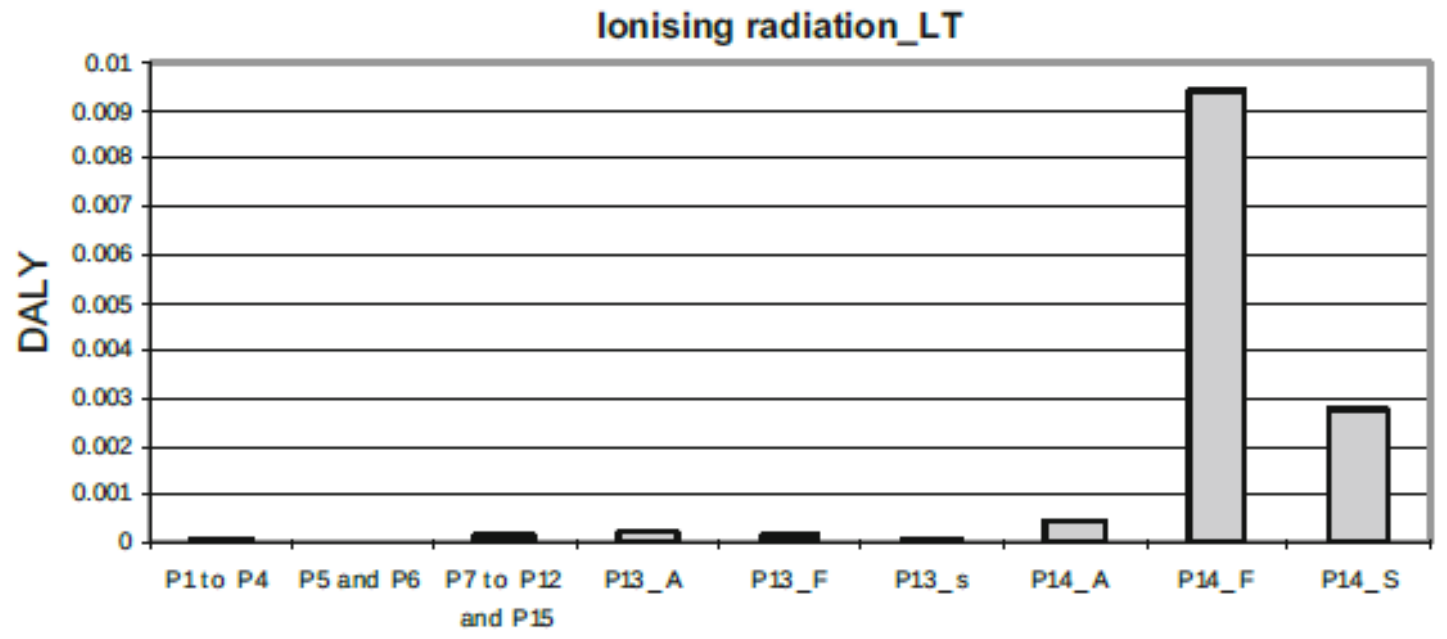

Processes 


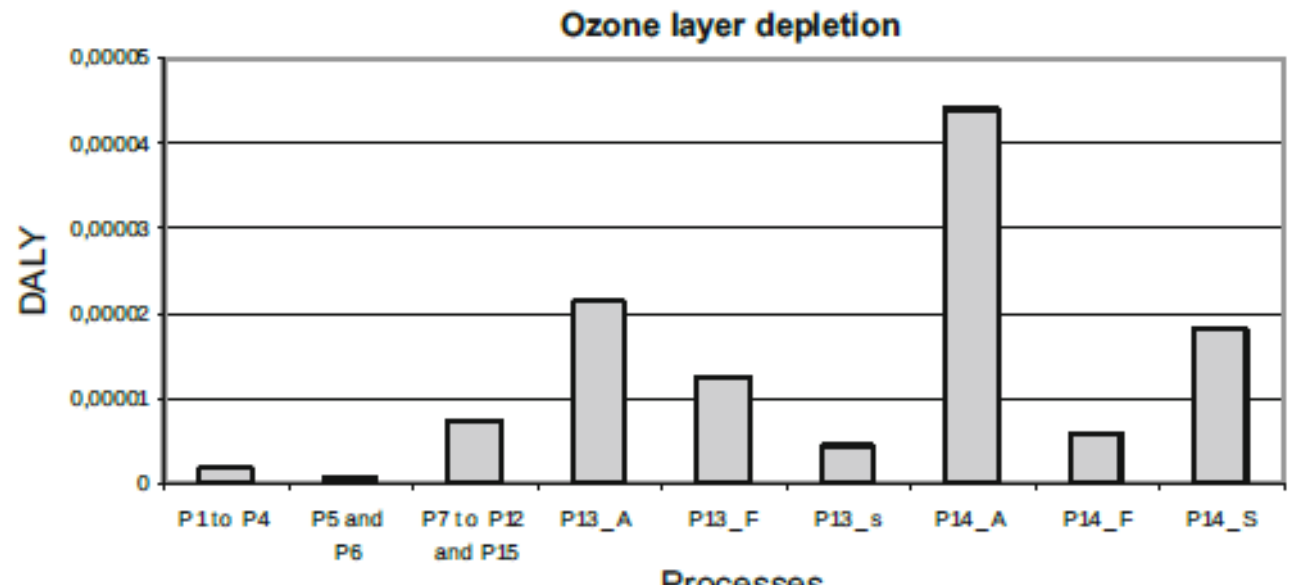

Processes
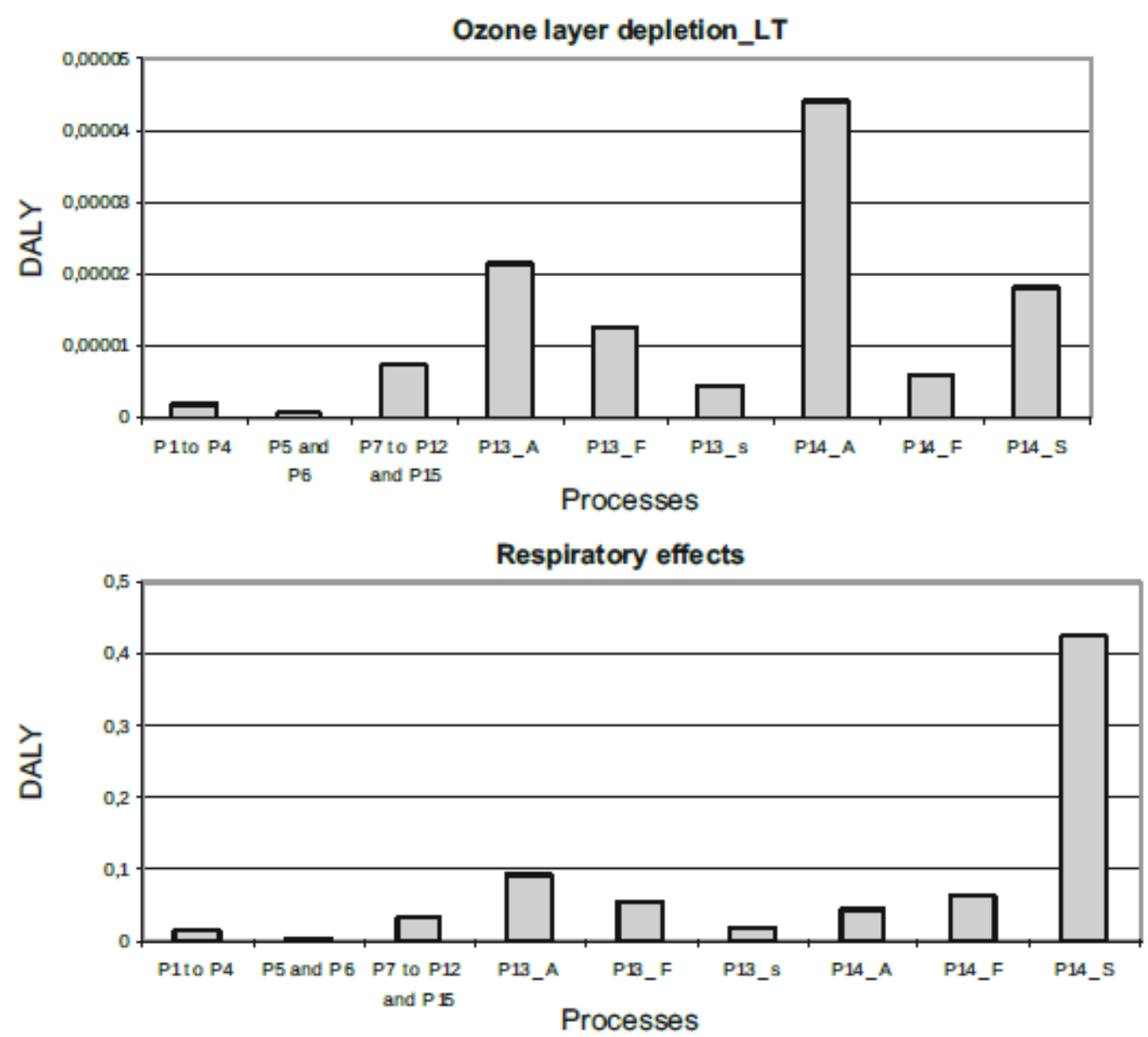


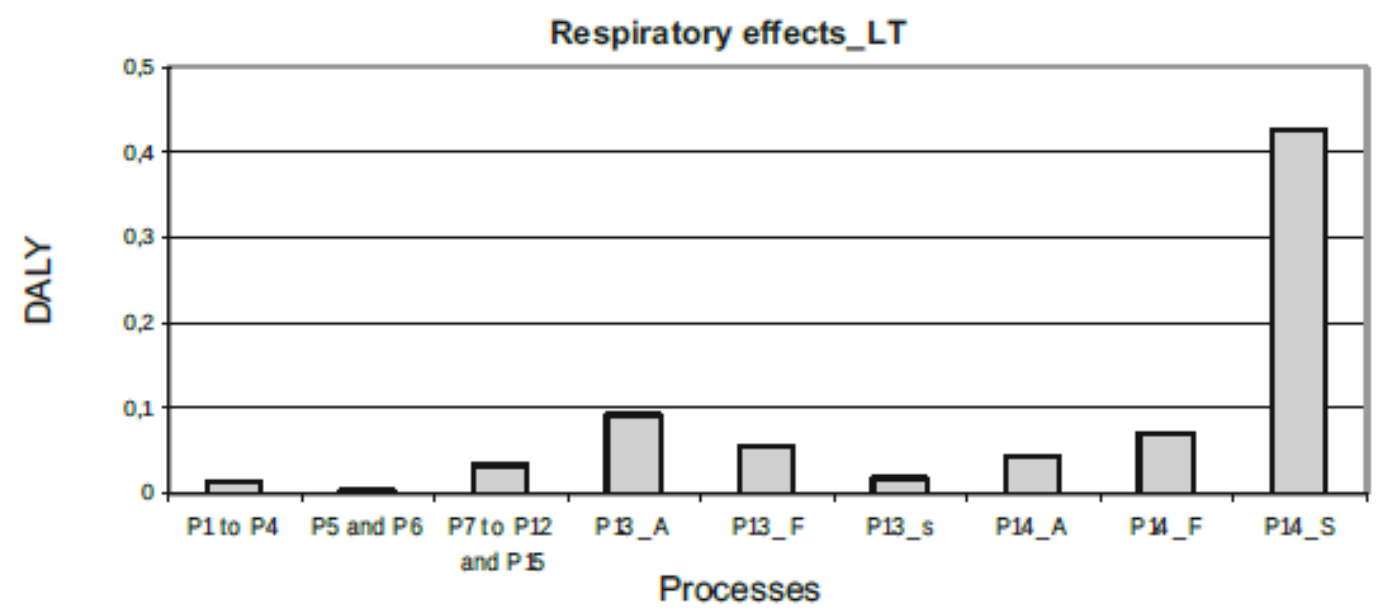

Fig. 8 Results of the impact assessment for the impact categories that belong to the damage category of human health (carcinogenic, climate change, ionising radiation, ozone layer depletion and respiratory effects),for the different processes, without and with inclusion of long-term emissions (graphics indicated with 'impact category_LT') 

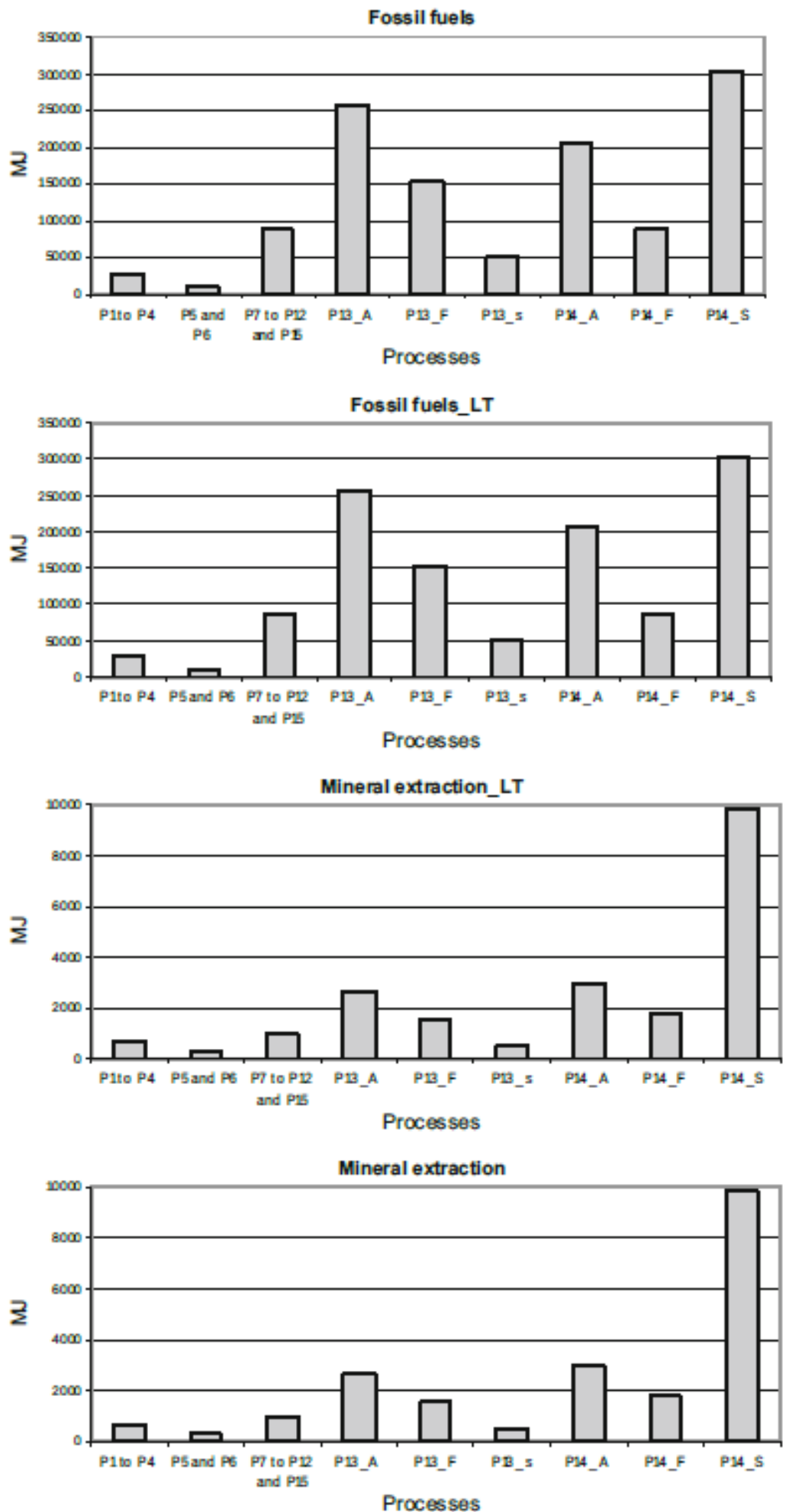

Fig. 9 Results of the impact assessment for the impact categories that belong to the damage category of resources (fossil fuel and mineral extraction), for the different processes, without and with inclusion of long-term emissions (graphics indicated with 'impact category_LT') 


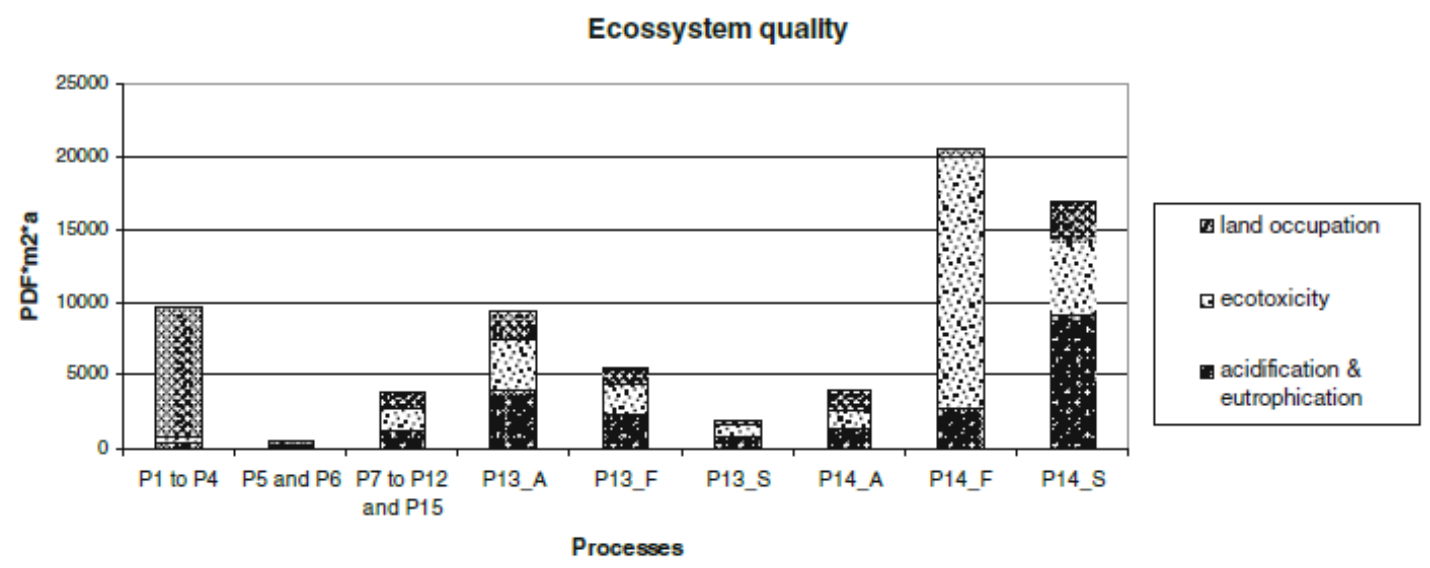

Human health

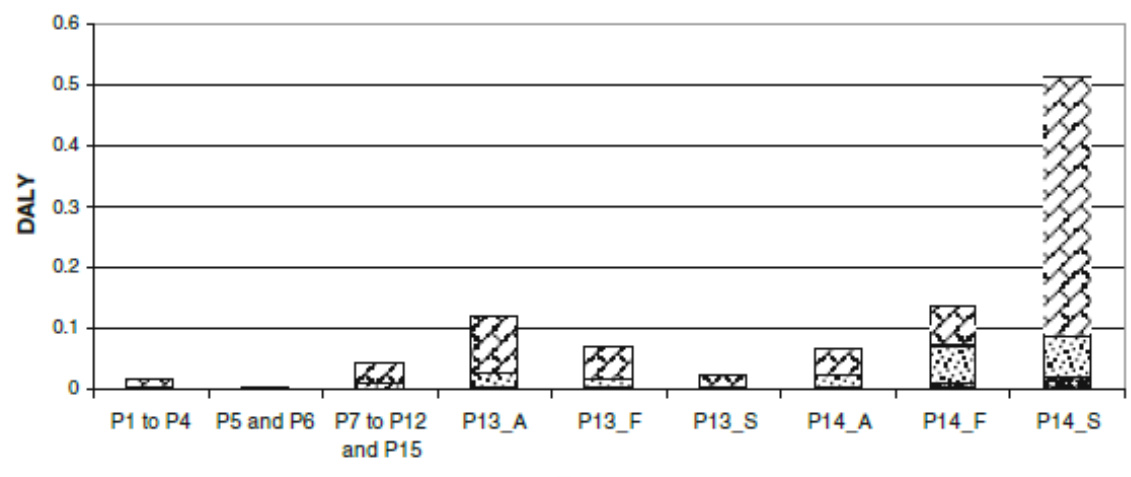

$\checkmark$ respiratory effects

- ozone layer depletion

teg ionising radiation

๑ climate change

a carcinogenics

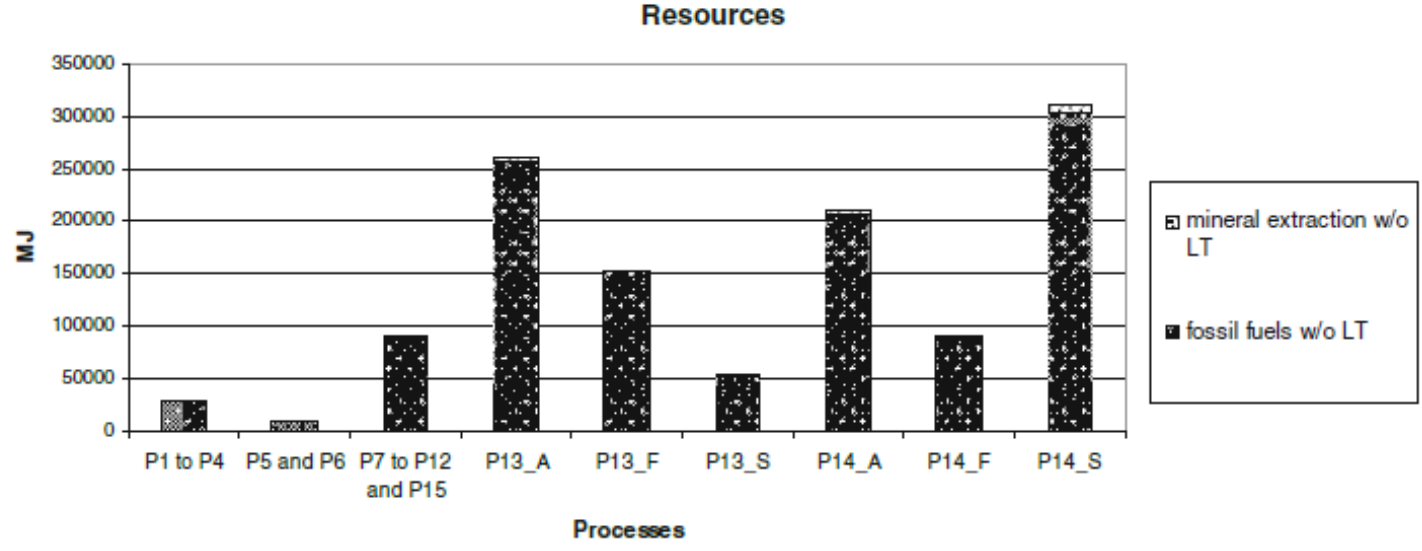

Fig. 10 Contribution of each impact category for the outcome of the respective damage category 

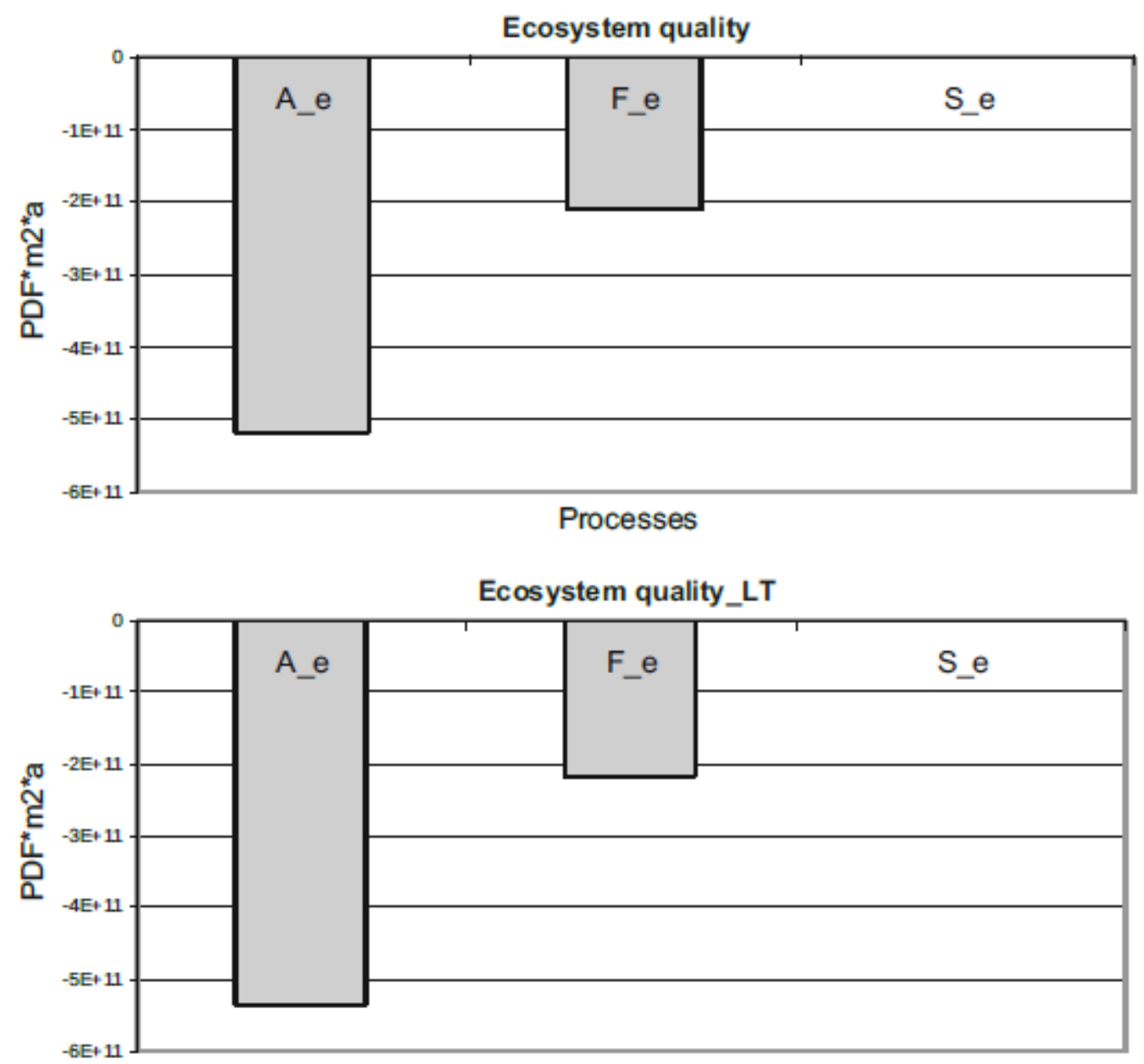

Processes

Human health

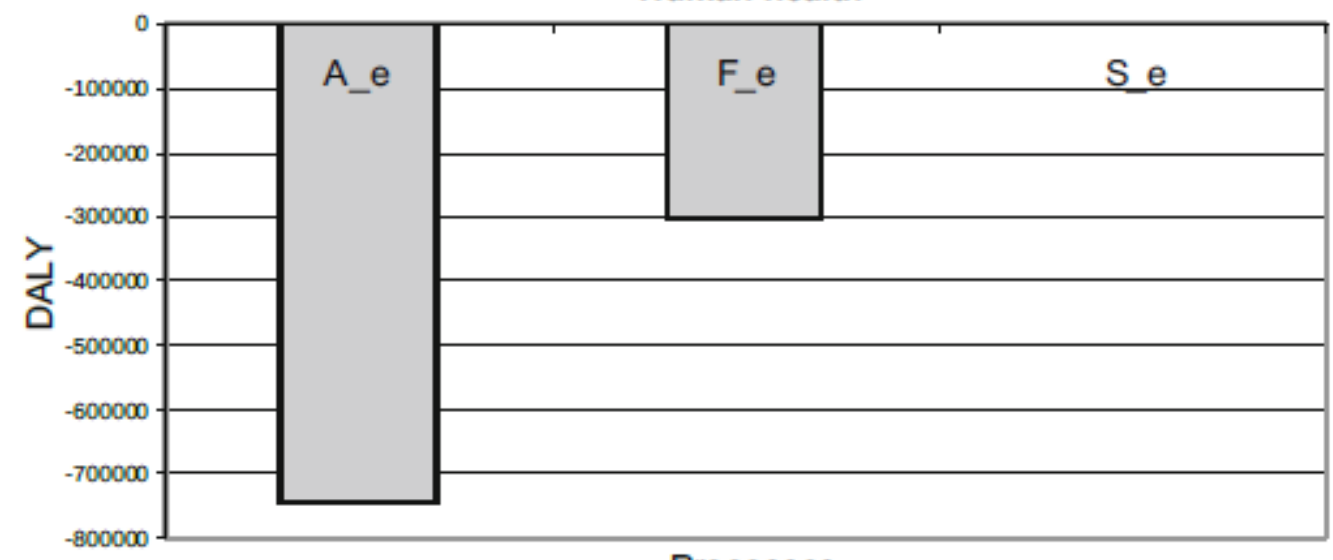

Processes 

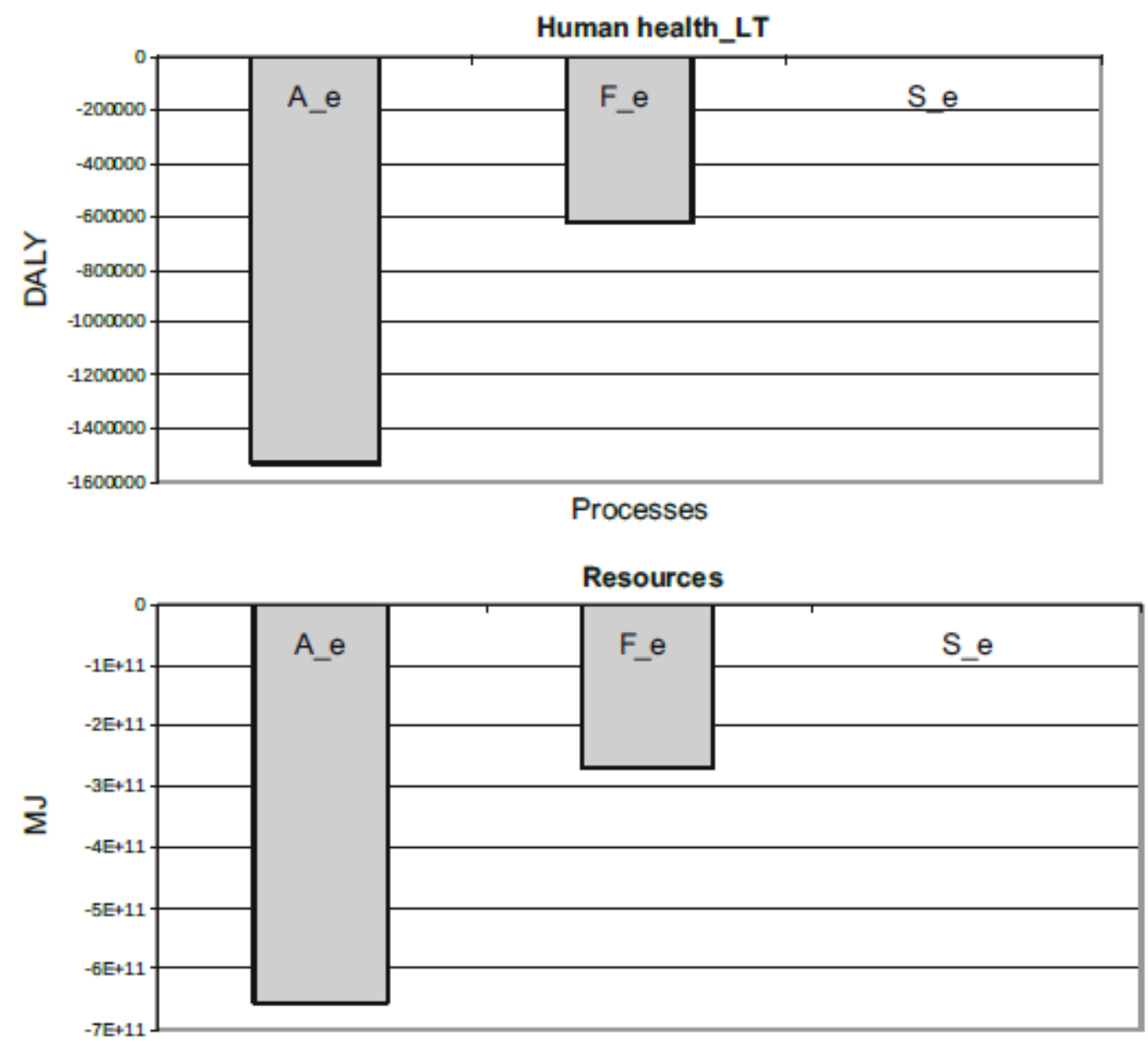

Processes

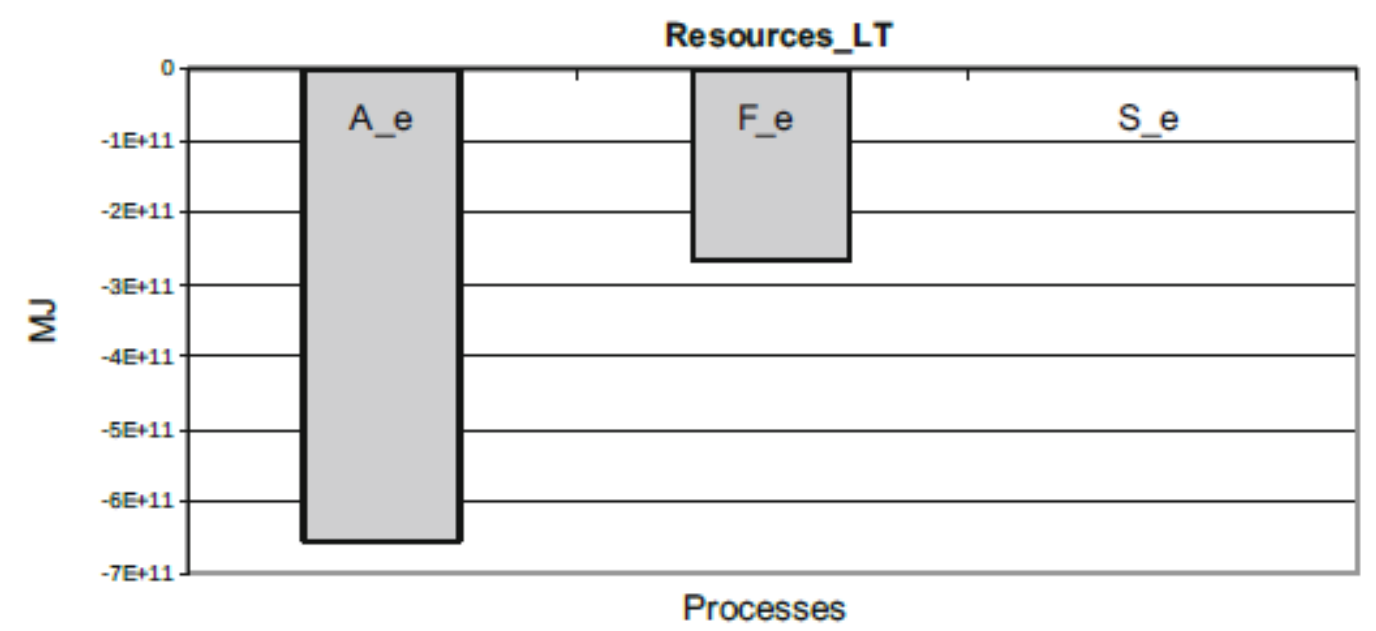

Fig. 11 Results obtained to avoid impacts due to material recovery occurring in the recycling processes of batteries (and quantified by the potential impact of obtaining virgin materials), for the different recycling processes, without and with inclusion of long-term emissions (graphics indicated with 'damage category_LT' 
Table 1 Inputs, source of data for the inventory and assumptions for the manufacture of containers, distribution of empty containers and battery collection and sorting processes

\begin{tabular}{|c|c|c|}
\hline Inputs & Amount & Source of inventory data \\
\hline \multicolumn{3}{|l|}{ Container manufacture processes } \\
\hline Production of kraftliner brown ${ }^{a}$ & $2,536 \mathrm{~kg}^{\mathrm{b}}$ & Corrugated board base paper, kraftliner, at plant/RER (Hischier 2007) \\
\hline Production of recycled fluting ${ }^{a}$ & $4,988 \mathrm{~kg}^{\mathrm{b}}$ & Corrugated board base paper, wellenstoff, at plant/RER (Hischier 2007) \\
\hline Production of kraftliner white ${ }^{a}$ & $2,401 \mathrm{~kg}^{\mathrm{b}}$ & Corrugated board base paper, kraftliner, at plant/RER (Hischier 2007) \\
\hline Production of recycled semi-chemical ${ }^{a}$ & $5,227 \mathrm{~kg}^{\mathrm{b}}$ & Corrugated board base paper, semi-chemical fluting, at plant/RER (Hischier 2007) \\
\hline Production of testliner white ${ }^{\mathrm{a}}$ & $2,070 \mathrm{~kg}^{\mathrm{b}}$ & Corrugated board base paper, testliner, at plant/RER (Hischier 2007) \\
\hline Transport of kraftliner brown & $1,014 \mathrm{tkm}^{\mathrm{c}}$ & Transport, lorry >32 t, EURO4/RER (Spielmann et al. 2007) \\
\hline Transport of recycled fluting & $9,477 \mathrm{tkm}^{\mathrm{c}}$ & Transport, lorry $>32 \mathrm{t}$, EURO4/RER (Spielmann et al. 2007) \\
\hline Transport of kraftliner white & $960 \mathrm{tkm}^{\mathrm{c}}$ & Transport, lorry $>32$ t, EURO4/RER (Spielmann et al. 2007) \\
\hline Transport of recycled semi-chemical & $7,840 \mathrm{tkm}^{\mathrm{c}}$ & Transport, lorry $>32 \mathrm{t}$, EURO4/RER (Spielmann et al. 2007) \\
\hline Transport of testliner white & $1,449 \mathrm{tkm}^{\mathrm{c}}$ & Transport, lorry $>32 \mathrm{t}$, EURO4/RER (Spielmann et al. 2007) \\
\hline Production of cardboard and inner box, Albarraque, Portugal & $4,880 \mathrm{~kg}$ & $\begin{array}{l}\text { Corrugated board, recycling fibre, double wall, at plant/RER (Hischier } 2007 \text { ) and } \\
\text { packaging, corrugated board, mixed fibre, single wall, at plant/RER } \text { R }^{d}\end{array}$ \\
\hline \multicolumn{3}{|l|}{ Distrbution of empty containers } \\
\hline Transport of boxes to MARL, Lisbon & $545 \mathrm{tkm}^{\mathrm{e}}$ & Transport, lorry 75-16 t, EURO4/RER (Spielmann et al. 2007) \\
\hline Transport of boxes: & $-e, f$ & Transport, van $<.5$ t/RER (Spielmann et al. 2007) \\
\hline $\begin{array}{l}\text { Lisbon Region } \\
\text { Littoral }\end{array}$ & $\begin{array}{l}172 \mathrm{tkm} \\
989 \mathrm{tkm}\end{array}$ & \\
\hline Porto Region & $856 \mathrm{tkm}$ & \\
\hline Northem Interior & $554 \mathrm{tkm}$ & \\
\hline Algarve & $152 \mathrm{tkm}$ & \\
\hline Southem Interior & $98 \mathrm{tkm}$ & \\
\hline \multicolumn{3}{|l|}{ Battery collection and sorting } \\
\hline $\begin{array}{l}\text { Battery collection: } \\
\text { Lisbon Region }\end{array}$ & $\stackrel{-g}{5,040 \mathrm{tkm}}$ & Transport, lony 35-7.5 t, EURO4/RER (Spielmann et al, 2007) \\
\hline Littoral & $29,040 \mathrm{tkm}$ & \\
\hline Porto Region & $25,160 \mathrm{tkm}$ & \\
\hline Northem Interior & $16,280 \mathrm{tkm}$ & \\
\hline Algarve & $4,480 \mathrm{tkm}$ & \\
\hline Southem Interior & $2,880 \mathrm{tkm}$ & \\
\hline Transport to sorting & $60,000 \mathrm{tkm}^{\mathrm{h}}$ & Transport, lorry >32 t, EURO4/RER (Spielmann et al. 2007) \\
\hline Production of stretch film & $90 \mathrm{~kg}^{\mathrm{i}}$ & Packaging film, LDPE, at plant/RER (Hischier 2007) \\
\hline
\end{tabular}

${ }^{a}$ Based on information from the company responsible for the manufacture of the boxes (Portucel Embalagem, personal communication; Europac Group, 2012), it was considered that the kraft papers are being produced in Viana, Portugal; the recycled fluting produced in France; and the testliner white produced in Spain. The semi-chemical paper is imported from Spain or France

${ }^{\mathrm{b}}$ With the plank area required for each box (Portucel Embalagem, personal communication) and assuming a cutting edge of $40 \mathrm{~mm}$, a corrugator loss of $3 \%$ and a take-up factor of 1.20 to flute E and 1.325 to flute B (FEFCO 2006), the required area of each paper was calculated, and with its grammage (Portucel Embalagem, personal communication), the required amount of each paper, in mass, was also calculated. In losses, parings of small cuts existing in the box were also accounted for (by the difference in mass between the plank used for the manufacture of the box and its final mass)

${ }^{\mathrm{c}}$ Transport distances were calculated using the Google Maps (https://maps.google.com/)

${ }^{\mathrm{d}}$ In the cardboard manufacture, the paper inventory and its transport were excluded (already previously considered in P1 and P2). The electrical matrix considered was the one from Portugal, whose inventory was also obtained from the Ecoinvent database (Frischknecht et al. 2007). For the manufacture of the boxes, neither the cardboard (already considered separately) nor the transport (since it does not exist because the boxes are produced in the same unit that produces the cardboard) was considered. The transportation was also not considered for auxiliary materials since this information was not available. The electrical matrix has been changed to the one of Portugal. The printing ink was considered as it is in the Ecoinvent process and polyethylene used for packing the boxes, too (despite being slightly lower than estimated). As in the production process of the boxes in Ecoinvent, a packaging system is considered, and since there is no detailed information about the system used in the studied boxes, no changes were introduced

${ }^{\mathrm{e}}$ In the load, only the mass of boxes was considered

${ }^{\mathrm{f}}$ Taking into account the amount of batteries collected in 2007 in each region, LR, LT, PR, NI, Al and SI (see Section 2.2.2), the number of boxes to be sent was calculated. Since most of the batteries are collected by municipal authorities responsible for the MSW management, it was considered that the transport distance of the boxes (whether empty or full) would be the average distance between Lisbon and the sorting plant of the MSW management entity of each region. In 2007, Portugal had 29 MSW management systems and only one had no sorting plant (Portuguese Environment Agency 2007); therefore, the distance from the location of its head unit was considered in the calculation

${ }^{\mathrm{g}}$ Transport distances considered were the same as for transportation of the empty boxes. In the load, only the mass of batteries was considered

${ }^{\text {h }}$ Each truck carries 22 pallets with about $20 \mathrm{t}$ of batteries (each pallet packs 36 boxes with about $25 \mathrm{~kg}$ of batteries each). The distance of transportation was calculated with the tool available in Google Maps (https://maps.google.com/). In the load, only the mass of batteries was considered

i The consumption of stretch film used in palletising the full boxes was estimated based on information obtained from one of the entities of MSW management that is involved in the collection of waste batteries (Lipor, personal communication) 
Table 2 Inputs, outputs and data source for the inventory of the battery recycling process in Austria (Fernwärme Wien)

\begin{tabular}{|c|c|c|}
\hline & Amount & Source of inventory data \\
\hline \multicolumn{3}{|l|}{ Inputs } \\
\hline Spent batteries & $1 \mathrm{t}$ & \\
\hline Oil (40-70 l/t) & 551 & Light fuel oil, at regional storage/RER (Jungbluth 2007) \\
\hline Electrical energy & $330 \mathrm{kWh}$ & Electricity, supply mix, medium voltage, at grid/AT (Frischknecht et al. 2007) \\
\hline TMT 15 & $1.7 \mathrm{~kg}$ & Triazine compounds, at regional storehouse/RER (Nemeck and Kägi 2007) \\
\hline $\mathrm{FeCl}_{3}(40 \%)$ & $25 \mathrm{~kg}$ & Iron (III) chloride, $40 \%$ in $\mathrm{H}_{2} \mathrm{O}$, at plant/CH (Althaus et al. 2007) \\
\hline $\mathrm{HCl}(30 \%)$ & $17 \mathrm{~kg}$ & Hydrochloric acid, $30 \%$ in $\mathrm{H}_{2} \mathrm{O}$, at plant/RER (Althaus et al. 2007) \\
\hline $\mathrm{CaO}$ & $17 \mathrm{~kg}$ & Limestone, crushed, washed/CH (Kellenberger et al. 2007) \\
\hline \multicolumn{3}{|l|}{ Outputs } \\
\hline Fine $\mathrm{ZnO}$ & $510 \mathrm{~kg}$ & $-{ }^{\mathrm{b}}$ \\
\hline Coarse $\mathrm{ZnO}$ & $110 \mathrm{~kg}$ & $\mathrm{~b}^{\mathrm{b}}$ \\
\hline $\mathrm{ZnO}$ Waelz & $190 \mathrm{~kg}$ & $\begin{array}{l}\overline{-}^{\mathrm{b}} \\
\text { Zinc concentrate, at beneficiation/GLO (Classen et al. 2009) }\end{array}$ \\
\hline Waelz slag & $430 \mathrm{~kg}$ & $\begin{array}{l}{ }^{\mathrm{b}} \\
\text { Mine, gravel/sand/CH (Kellenberger et al. 2007) }\end{array}$ \\
\hline Scrap & $150 \mathrm{~kg}$ & Iron scrap, at plant/RER (Classen et al. 2009) \\
\hline Wastewater & $9 \mathrm{~m}^{3}$ & 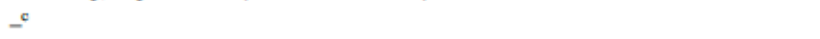 \\
\hline Filter cake & $33 \mathrm{~kg}$ & Waste management/residual material landfill process-specific burdens/CH (Doka 2009) \\
\hline \multicolumn{3}{|l|}{ Air emissions } \\
\hline Dust & $0.5 \mathrm{mg} / \mathrm{m}^{3}$ & Considered particulates $<2.5 \mu \mathrm{m}$ \\
\hline $\mathrm{HCl}$ & $0.55 \mathrm{mg} / \mathrm{m}^{3}$ & \\
\hline $\mathrm{SO}_{2}$ & $<3 \mathrm{mg} / \mathrm{m}^{3}$ & ${ }^{d}$ \\
\hline $\mathrm{CO}$ & $25 \mathrm{mg} / \mathrm{m}^{3}$ & Considered fossil, unspecified \\
\hline $\mathrm{NO}_{x}$ & $30 \mathrm{mg} / \mathrm{m}^{3}$ & \\
\hline Sum metals $(\mathrm{Pb}+\mathrm{Zn})$ & $0.001 \mathrm{mg} / \mathrm{m}^{3}$ & Considered equal amounts of $\mathrm{Pb}$ and $\mathrm{Zn}$ \\
\hline $\mathrm{Hg}$ & $<0.002 \mathrm{mg} / \mathrm{m}^{3}$ & $-d^{d}$ \\
\hline$C_{\text {org }}$ & $1 \mathrm{mg} / \mathrm{m}^{3}$ & Considered NMVOC. \\
\hline $\mathrm{PCDD} / \mathrm{PCDF}$ & $0.004 \mathrm{ng} / \mathrm{m}^{3}$ & Considered equal amounts of dioxins and furans \\
\hline
\end{tabular}

${ }^{a}$ Although the chemical properties of the triazine are not comparable to TMT 15 , its inventory was considered to be the most similar chemical

${ }^{b}$ As stated in its description, the result of this recycling process are two fractions of $\mathrm{ZnO}$, fine and coarse that are recovered as $\mathrm{ZnO}$ and a Waelz slag. Since the accounting of these products is only indicative (see Section 2.2.11), the products that they will replace were considered for the inventory of avoided burdens. In reality, the Waekz process also has environmental loads that are not considered in the present study

${ }^{\mathrm{c}}$ This flow is not considered per se because the materials and energy needed for its treatment are already accounted for

${ }^{\mathrm{d}}$ Emissions accounted for by its upper limit, i.e. equal to the indicated value 
Table 3 Inputs, outputs and data source for the inventory of the battery recycling process in France (VALDI)

\begin{tabular}{|c|c|c|}
\hline & Amount & Source of inventory data \\
\hline \multicolumn{3}{|l|}{ Inputs } \\
\hline Spent batteries & $1 \mathrm{t}$ & \\
\hline Natural gas & $30 \mathrm{kWh}$ & Natural gas, high pressure, at consumer/FR (Faist Emmenegger et al. 2007) \\
\hline Electricity & $1,000 \mathrm{kWh}$ & Electricity, medium voltage, at grid, supply mix/FR (Frischknecht et al. 2007) \\
\hline FeSi waste & $15 \mathrm{~kg}^{\mathrm{a}}$ & Iron scrap, at plant/RER (Classen et al. 2009) \\
\hline Carbon waste & $17.5 \mathrm{~kg}^{\mathrm{a}}$ & Petroleum coke, at refinery/RER (Jungbluth 2007) \\
\hline Steel scrap & $2 \mathrm{~kg}^{\mathrm{a}}$ & Iron scrap, at plant/RER (Classen et al. 2009) \\
\hline Lime $(\mathrm{CaO})$ & $15 \mathrm{~kg}^{\mathrm{a}}$ & Limestone, crushed, washed/CH (Kellenberger et al. 2007) \\
\hline Water & $0.01 \mathrm{~m}^{3}$ & Production tap water, at user/RER (Althaus et al. 2007) \\
\hline \multicolumn{3}{|l|}{ Outputs } \\
\hline Ferromanganese alloy & $375 \mathrm{~kg}^{\mathrm{a}}$ & Ferromanganese, high coal, $74.5 \% \mathrm{Mn}$, at regional storage/RER (Classen et al. 2009) \\
\hline Filter dust & $300 \mathrm{~kg}^{\mathrm{a}}$ & Zinc concentrate, at beneficiation/GLO (Classen et al. 2009) ${ }^{\mathrm{b}}$ \\
\hline Slag & $175 \mathrm{~kg}^{\mathrm{a}}$ & Mine, gravel/sand/CH (Kellenberger et al. 2007) $)^{b}$ \\
\hline \multicolumn{3}{|l|}{ Air emissions } \\
\hline $\mathrm{CO}_{2}$ & $600 \mathrm{~kg}$ & Considered fossil, unspecified \\
\hline $\mathrm{CO}$ & $1,100 \mathrm{~g}^{\mathrm{a}}$ & Considered fossil, unspecified \\
\hline $\mathrm{NO}_{x}$ & $800 \mathrm{~g}^{\mathrm{a}}$ & \\
\hline $\mathrm{SO}_{x}$ & $120 \mathrm{~g}^{\mathrm{a}}$ & Considered sulfur dioxide \\
\hline Dust & $10 \mathrm{~g}^{\mathrm{a}}$ & Considered particulates $<2.5 \mu \mathrm{m}$ \\
\hline As & $<0.04 \mathrm{~g}$ & 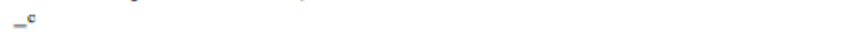 \\
\hline $\mathrm{Cd}$ & $<0.2 \mathrm{~g}$ & $-^{c}$ \\
\hline $\mathrm{Cr}$ & $<8 \mathrm{~g}$ & $-^{c}$ \\
\hline $\mathrm{Cu}$ & $<0.2 \mathrm{~g}$ & $-\mathrm{c}$ \\
\hline $\mathrm{Hg}$ & $<0.04 \mathrm{~g}$ & $-^{c}$ \\
\hline $\mathrm{Ni}$ & $<0.2 \mathrm{~g}$ & $-c$ \\
\hline $\mathrm{Pb}$ & $<0.2 \mathrm{~g}$ & $-^{c}$ \\
\hline $\mathrm{Zn}$ & $<0.96 \mathrm{~g}$ & $-{ }^{\mathrm{c}}$ \\
\hline Dioxins and furans & $<4 \times 10^{-11} \mathrm{~g}$ & $\begin{array}{l}-^{c} \\
\text { Considered equal amounts of dioxins and furans }\end{array}$ \\
\hline Mn & $<0.2 \mathrm{~g}$ & $-c$ \\
\hline
\end{tabular}

${ }^{\mathrm{a}}$ Considered the mean value of the range presented in the original inventory

${ }^{\mathrm{b}}$ Since the accounting of these products is only indicative (see Section 2.2.11), the products that they will replace were considered for the inventory of avoided burdens

${ }^{\mathrm{c}}$ Emissions accounted for by its upper limit, i.e. equal to the indicated value 
Table 4 Inputs, outputs and data source for the inventory of the battery recycling process in Spain (Recupyl)

\begin{tabular}{|c|c|c|}
\hline & Amount & Source of inventory data \\
\hline \multicolumn{3}{|l|}{ Inputs } \\
\hline Spent batteries & $1 \mathrm{t}$ & \\
\hline Electricity & $960 \mathrm{kWh}$ & Electricity, supply mix, medium voltage, at grid/ES (Frischknecht et al, 2007) \\
\hline $\mathrm{H}_{2} \mathrm{SO}_{4}(92 \%)$ & 1681 & $100 \%$ sulphuric acid, liquid, at plant/RER (Althaus et al. 2007$)^{\mathrm{a}}$ \\
\hline $\mathrm{H}_{2} \mathrm{O}_{2}(30 \%)$ & 1261 & $50 \%$ hydrogen peroxide, $50 \%$ in $\mathrm{H}_{2} \mathrm{O}$, at plant/RER (Althaus et al. 2007) \\
\hline Antifoam & 0.861 & Chemicals organic, at plant/GLO (Althaus et al. 2007) \\
\hline Water & 5701 & Production tap water, at user/RER (Althaus et al. 2007) \\
\hline \multicolumn{3}{|l|}{ Outputs } \\
\hline Zinc & $205 \mathrm{~kg}$ & Zinc, primary, at regional storage/RER (Classen et al. 2009) ${ }^{c}$ \\
\hline $\begin{array}{l}\text { Manganese dioxide } \\
\text { - Pure manganese }\end{array}$ & $\begin{array}{l}317 \mathrm{~kg} \\
228 \mathrm{~kg}\end{array}$ & Manganese, at regional storage/RER (Classen et al. 2009) ${ }^{c}$ \\
\hline Iron and steel & $180 \mathrm{~kg}$ & Pig iron, at plant/GLO (Classen et al. 2009) ${ }^{\mathrm{c}}$ \\
\hline \multicolumn{3}{|l|}{ Emissions to air } \\
\hline $\mathrm{NH}_{3}$ & $0.005 \mathrm{~kg}$ & \\
\hline Dust & $0.0015 \mathrm{~g}$ & Considered particulates $<2.5 \mu \mathrm{m}$ \\
\hline $\mathrm{Hg}+\mathrm{Cd}$ & $0.00003 \mathrm{~kg}$ & Considered equal amounts of $\mathrm{Hg}$ and $\mathrm{Cd}$ \\
\hline Acid & $0.000084 \mathrm{~kg}$ & Considered $\mathrm{HCl}$ \\
\hline $\mathrm{H}_{2}, \mathrm{O}_{2}$, water & $29.61 \mathrm{~kg}$ & In the inventory was only recorded as water \\
\hline $\mathrm{Zn}+\mathrm{Mn}$ & $0.00001316 \mathrm{~kg}$ & Considered equal amounts of $\mathrm{Zn}$ and $\mathrm{Mn}$ \\
\hline $\mathrm{O}_{2}$ & $39 \mathrm{~kg}$ & \\
\hline \multicolumn{3}{|l|}{ Emissions to water } \\
\hline Solid suspension & $0.0119 \mathrm{~kg}$ & \\
\hline $\mathrm{Hg}$ & $0.0000028 \mathrm{~kg}$ & \\
\hline $\mathrm{Cd}$ & $0.000007 \mathrm{~kg}$ & \\
\hline $\mathrm{Zn}$ & $0.0028 \mathrm{~kg}$ & \\
\hline Mn & $0.00224 \mathrm{~kg}$ & \\
\hline Water+acid & $768 \mathrm{~kg}$ & $-{ }^{\mathrm{d}}$ \\
\hline Water release & 99 kg & Wastewater treatment, class 3/CH (Doka 2009). With replacement of electric mix of CH by ES \\
\hline Paper/plastic & $120 \mathrm{~kg}$ & $\begin{array}{l}\text { Waste management, landfill process-specific burdens/CH (Doka 2009). With replacement of } \\
\text { electric mix of CH by ES }\end{array}$ \\
\hline $\begin{array}{l}\text { Residue of leaching (chemical } \\
\text { treatment) }\end{array}$ & $97 \mathrm{~kg}$ & $\begin{array}{l}\text { Waste management, landfill process-specific burdens/CH (Doka 2009). With replacement of } \\
\text { electric mix of CH by ES }\end{array}$ \\
\hline Mixed heavy metals & $10 \mathrm{~kg}$ & $\begin{array}{l}\text { Waste management, landfill process-specific burdens/CH (Doka 2009). With replacement of } \\
\text { electric mix of CH by ES }\end{array}$ \\
\hline
\end{tabular}

${ }^{\mathrm{a}}$ It was assumed to have a density of $1.84 \mathrm{~kg} / \mathrm{l}$

${ }^{\mathrm{b}}$ It was assumed to have a density of $1.2 \mathrm{~kg} / \mathrm{l}$

' Since the accounting of these products is only indicative (see Section 2.2 .11 ), the products that they will replace were considered for the inventory of avoided burdens

${ }^{\mathrm{d}}$ This flow was not considered because it is recirculated in the process 